\title{
Rheological Properties of Defense Waste Slurries
}

\author{
Topical Report \\ January 1998
}

\author{
By: \\ M. A. Ebadian
}

RECEIVEO

OCT 261998

OSTI

Work Performed Under Contract No.: DE-FG21-95EW55094

For

U.S. Department of Energy

Office of Fossil Energy

Federal Energy Technology Center

P.O. Box 880

Morgantown, West Virginia 26507-0880

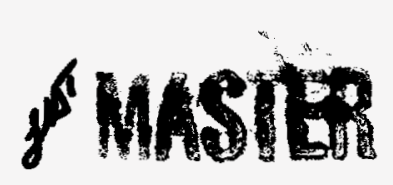

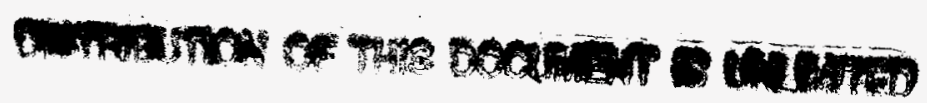

By

Florida International University

Hemispheric Center for Environmental Technology (HCET)

Center for Engineering \& Applied Sciences

10555 West Flagler Street

EAS-2100

Miami, Florida 33174 


\section{Disclaimer}

This report was prepared as an account of work sponsored by an agency of the United States Government. Neither the United States Government nor any agency thereof, nor any of their employees, makes any warranty, express or implied, or assumes any legal liability or responsibility for the accuracy, completeness, or usefulness of any information, apparatus, product, or process disclosed, or represents that its use would not infringe privately owed rights. Reference herein to any specific commercial product, process, or service by trade name, trademark, manufacturer, or otherwise does not necessarily constitute or imply its endorsement, recommendation, or favoring by the United States Government or any agency thereof. The views and opinions of authors expressed herein do not necessarily state or reflect those of the United States Government or any agency thereof. 


\section{DISCLAIMER}

Portions of this document may be illegible in electronic image products. Images are produced from the best available original document. 
The results presented in this report were obtained from the work supported by the $\mathrm{U}$. S. Department of Energy (DOE), Environmental Management (EM), Office of Science and Technology (OST) under Grant No. DE-FG01-95EW55094. The Principal Investigator and the associate researchers at the Hemispheric Center for Environmental Technology would like to thank Dr. E. W. Holtzscheiter, Manager of Advanced Applications, Westinghouse Savannah River Technology Center (SRTC), for his guidance and suggestions on this project. Many: discussions and consultations with SRTC's technical staff have contributed greatly to this research. We would especially like to thank the DOE-OST, for their support and encouragement throughout this research. 


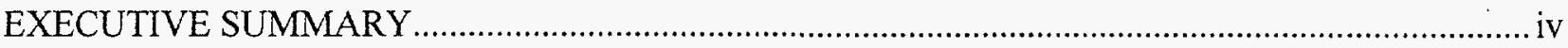

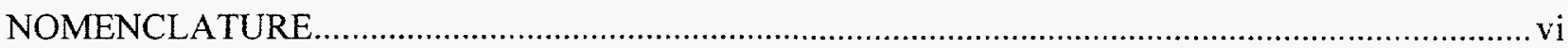

1.0 INTRODUCTION

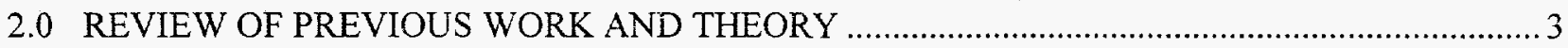

2.1 SLURRY VISCOSITY AS A FUNCTION OF ITS PROPERTIES ………………………... 3

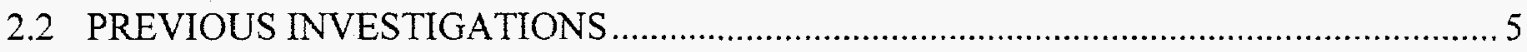

3.0 EXPERIMENTAL SETUP AND SAMPLE PREPARATION …………………………………....

3.1 BATCH OPERATION MODE: CONCENTRIC CYLINDER

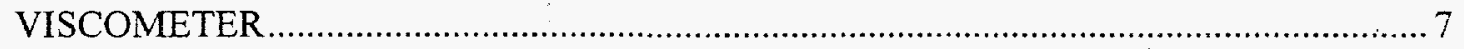

3.2 CONTINUOUS OPERATING MODE: PIPELINE FLOW SYSTEM ............................... 10

3.3 EXPERIMENTAL SET UP FOR SETTLING TESTING …………………………….......11

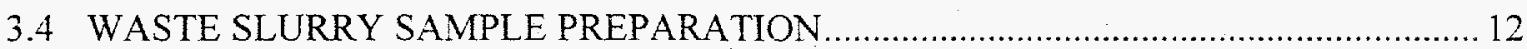

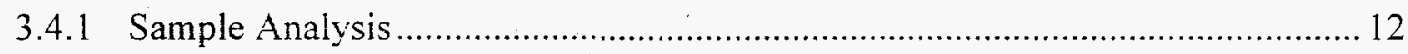

3.4.2 Sample Preparation ................................................................................... 15

4.0 EXPERIMENTAL STUDY USING A ROTATIONAL VISCOMETER ………….......................17

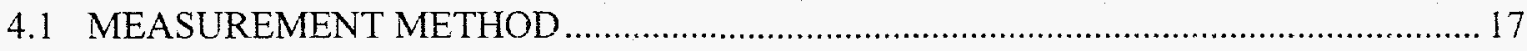

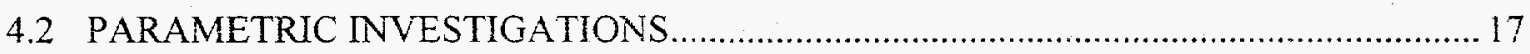

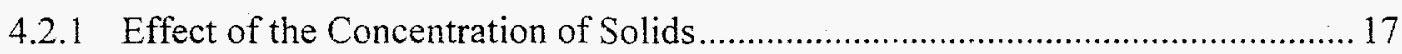

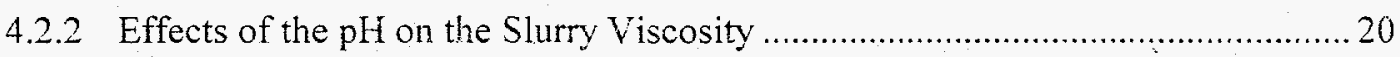

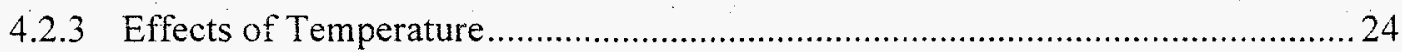

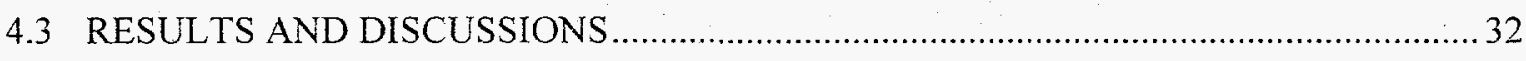

5.0 EXPERIMENTAL STUDY USING THE PIPELINE FLOW SYSTEM ………………………........

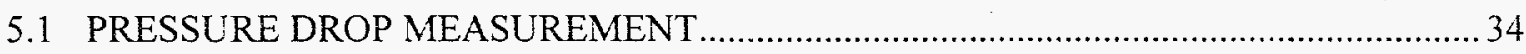

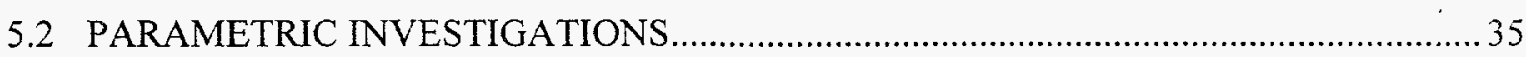

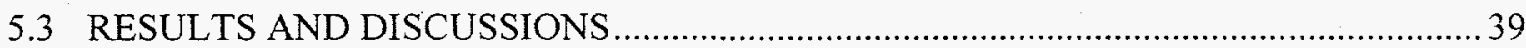

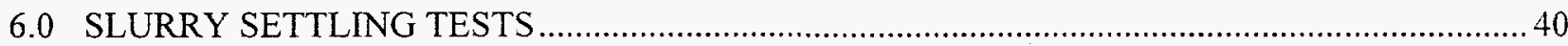

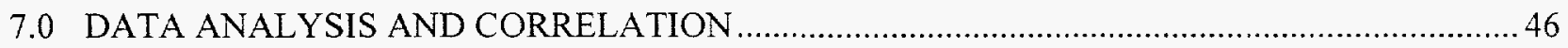

8.0 MAJOR ACCOMPLISHMENTS AND CONCLUSIONS .......................................................... 48

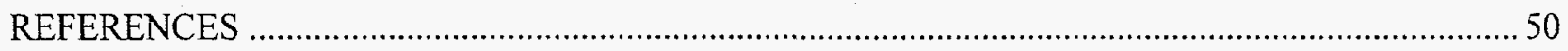




\section{EXECUTIVE SUMMARY}

The rheological property measurement and correlation for the defense waste slurry carried out by the Hemispheric Center for Environmental Technology (HCET) at Florida International University (FIU) for fiscal years 1996 (FY96) and 1997 (FY97) have been summarized in this final report. The objective of this project has been to address the need for rheological information to prepare the melter feeds in the nuclear waste vitrification process. The focus of the research has been experimental study and model development for prediction and control of the feed rheological properties. The refined and reliable experimental data on the rheological properties obtained from this work can be used to enhance the current design base for waste slurry mixing and transportation systems, to improve the process' performance, to increase the operating safety, and to reduce vitrification costs.

During the execution of this project, collection and analysis of experimental data for the rheological behavior of simulated meiter feeds has been emphasized. Due to the unique properties of nuclear waste, much effort has been made to validate the experimental facility, collect experimental data, and correlate the observed data. In contrast to earlier rheological studies of melter feeds that covered relatively narrow parameter ranges, this study covers a wider range of solids concentrations, $\mathrm{pH}$ values, temperature, and flow rate. The simulated waste slurry, which was composed of water, soluble metal salts, and insoluble solid particles, was obtained from DOE sites. This particular mixture was used to simulate the actual product of a defense waste treatment process. The apparent viscosity of the waste slurry was measured under various feed and operating conditions in two measurement systems: direct viscosity measurement using a viscometer and pressure drop measurement using a pipeline test loop.

The experimental results indicate that the viscosity of the slutry is sensitive to the concentration of solids, temperature, and the $\mathrm{pH}$ of the solution. The measured viscosity has been correlated as a function of the solids contents based on fundamental fluid rheology theory. Special parameters were included in the model to describe various feed condition effects on the rheological behavior.

The effects of the important parameters on the viscosity of the selected waste slurriestemperature and slurry chemical nature - were identified. For the Savannah River (SRS) waste slurry simulant, operating temperature has been found to have different effects on viscosity in different concentration ranges. For the Hanford slurry simulant, the slurry viscosity increases as the temperature increases for all concentration ranges. Experimental observations of the effect of the $\mathrm{pH}$ indicate that there is a viscosity peak around the $\mathrm{pH}$ value of 8 for the Hanford slurry; while the viscosity of SRS slurry increases as the pH increases from 4 to 13.5. At higher slurry temperatures, increased slurry viscosity in certain solids concentration ranges was observed, but the effect is less significant than that of concentration and $\mathrm{pH}$.

In addition to the viscosity and pressure drop measurements, the settling behavior of the particles in the slurry was investigated using graduated cylinders. Settling velocity has been measured for both the SRS and Hanford slurries. The effects of slurry concentration and $\mathrm{pH}$ on the settling velocity were examined.

It is expected that the application of these experimental and modeling results to the vitrification melter feeds preparation process can lead to the modification and enhancement of the technical 
base for the design of slurry transportation equipment and pipeline systems. The results also serve as important references for improving waste slurry mixing performance. All of these factors will contribute to improvements in the vitrification process and the safety of final waste glass disposal. 
A Parameter in the viscosity model (cP)

Am Reading of pressure transducer (Am)

$\mathrm{A}_{0} \quad$ Reading of pressure transducer at zero flow rate of slurry (Am)

B Parameter in the viscosity model

C, $\mathrm{C}_{\mathrm{s}} \quad$ Solids concentration in the slurry (wt. \%)

$\mathrm{C}_{\max } \quad$ Maximum solids concentration in the slurry (wt. \%)

D Parameter in the viscosity model or Diameter of testing pipe (m)

d diameter of particle $(\mathrm{m})$

F Calibration factor of pressure transducer

g Gravitational acceleration $(\mathrm{m} / \mathrm{s} / \mathrm{s})$

$\mathrm{P}_{1} \quad$ Pressure at inlet of testing section (psi)

$\mathrm{P}_{2} \quad$ Pressure at outlet of testing section (psi)

$\triangle \mathrm{P} \quad$ Pressure drop along the testing section of pipeline $(\mathrm{cP})$

$\mathrm{L} \quad$ Length of the test section of the pipeline [m]

$\mathrm{T}$ Temperature $\left[{ }^{\circ} \mathrm{C}\right]$

$\mathrm{v}_{\mathrm{t}} \quad$ Terminal velocity of particle setting $(\mathrm{m} / \mathrm{s})$

$\mathrm{W}_{\mathrm{gross}}$. Total weight of beaker and wet sample of slurry (gram)

$\mathrm{W}_{\text {gross }} \quad$ Weight of beaker (gram)

$\mathrm{W}_{\text {gross }} \quad$ Total weight of beaker and dry sample of slurry (gram)

\section{Greek Symbols}

$\mu \quad$ Apparent viscosity of the slurry [cP]

$\tau_{\omega} \quad$ Shear stress applied on the internal tube wall (psi)

\section{Subscripts}

max Maximum solids concentration of the slurry

$0 \quad$ Zero slurry flow rate in pipeline 


\subsection{INTRODUCTION}

This project, which began in FY96, involves the development of reliable methods and data for the measurement, prediction, and control of the rheological properties of defense waste slurries involved in the melter feeds preparation system for defense waste vitrification. The measurement results for the melter feeds are critical to the establishment of transport parameters that are needed for the design of transportation and handling equipment. A technical requirement is that the yield stress and consistency of the slurries in the transportation pipelines and melter feed tanks (MFT) be within the design bases of key equipment. The current process operating constraint used to control the properties within these limits is to maintain the total solids concentration in a specified range of solids concentration. Practical experience and the study of slurries indicate that the rheological properties need to be investigated over a wider solids concentration and other parameter ranges to provide more reliable information for current operation improvement and future process design.

FIU-HCET has conducted these experiments and analyses. The resulting data and correlated model will be available for the design and selection of the key equipment used to process the various sludge types throughout the DOE Complex. During the execution of the project, multiple levels of solid concentrations, temperature, and $\mathrm{pH}$ values have been investigated, and the experimental results have been correlated with an appropriate rheological model.

Over the past 45 years, the United States has generated over $1.7 \times 10^{8}$ gallons of HLW, most of which is a result of the military program for defense weapons production. For example, at the SRS, spent fuel from the Department of Defense reactors was used to reclaim plutonium and uranium. The remaining radioactive materials, fission products, fuel components, and nonradioactive chemicals used in processing make up the HLW stored in underground tanks. The most hazardous of these wastes, HLW is a pressing environmental concern that is considered a high priority for treatment and permanent disposal.

The Defense Waste Processing Facility (DWPF) at the SRS is currently implementing advanced environmental technologies, including the vitrification process, to treat HLW. Waste vitrification is a thermal process operated at high temperatures $\left(1100-1350^{\circ} \mathrm{C}\right)$ to melt the $\mathrm{HLW}$ waste with silicon or other glass-based additives to produce a durable waste glass form. In this way, the hazardous and radioactive elements in the HLW are immobilized by incorporating them into borosilicate glass. The glass form will be permanently disposed of in a geologic repository. The vitrification technology has been developed and validated for full-scale operation at the SRS and other DOE sites.

Vitrification melter feeds are composed of waste slurry, supernate, and glass-based additives. Many requirements must be satisfied before the melter feed is considered suitable for use in nuclear waste vitrification. Because of the multicomponent and multiphase nature of the waste stream, the performance of the vitrification equipment and the durability of the glass product depend significantly on the properties of the melter feed. These important properties include composition, mixing uniformity, and rheological behavior. 
The rheological properties of the melter feed not only affect the performance of the resulting glass product and the operation of the process but also serve as a technical base for process designs and modifications. For example, to design the slurry mixing system and calculate the power consumption for the agitation motor, the viscosity of the slurry must be identified. To handle and transport the mixed feed to the vitrification melter, the slurry pump and pipeline system must be designed based on detailed information on the rheological properties of the waste slurry. Moreover, the economy and cost of the process can be optimized if a reasonable balance is established between the cost of the transportation of the slurry, which directly relates to the rheological properties, and the consumption of power, which is used to evaporate the water in the slurry stream during the vitrification process in the melter.

The major objective of this two-year project has been to obtain refined and reliable experimental data about the rheological properties of melter feeds. The research has involved both experimental studies and model development. Two experimental facilities have been set up to measure viscosity and pressure drop. Mathematical models have been developed as a result of experimental observation and fundamental theological theory. The model has the capability to predict the viscosity of melter slurries in a range of experimental conditions. The final results of the investigation could be used to enhance the current design base for slurry transportation systems and improve the performance of the slurry mixing process. If successful, the cost of this waste treatment will be reduced, and disposal safety will be increased.

The specific objectives for this project included: (1) the design, implementation, and validation of the experimental facility in both batch and continuous operating modes; (2) the identification and preparation of melter feed samples of both the SRS and Hanford waste slurries at multiple solids concentration levels; (3) the measurement and analysis of the melter feeds to determine the effects of the solids concentration, $\mathrm{pH}$ value, and other factors on the rheological properties of the slurries; (4) the correlation of the rheological properties as a function of the measured physical and chemical parameters; and (5) transmission of the experimental data and resulting correlation to the DOE site user to guide melter feed preparation and transport equipment design. 


\subsection{REVIEW OF PREVIOUS WORK AND THEORY}

\subsection{SLURRY VISCOSITY AS A FUNCTION OF ITS PROPERTIES}

Many operating parameters and feed variables can affect the rheological properties of waste slurries. These include temperature, concentration of the solute, molecular weight of the solute, pressure, suspended matter, and $\mathrm{pH}$ value. The following are brief descriptions of these factors and their influence on the rheology of the slurry.

\section{Temperature}

An inverse relationship exists between viscosity and temperature for most of the fluids. Typical data are shown in Figure 1, which plots the viscosity of solutions with different concentrations as a function of temperature. It can be noted in the bottom curve in the figure that the viscosity of S200 at $20^{\circ} \mathrm{C}$ is 580 centipoises $(\mathrm{cP})$, and it falls steadily to $14 \mathrm{cP}$ at $100^{\circ} \mathrm{C}$. However, it is possible that, for some special non-Newtonian fluids, this inverse relationship is not applicable. From this investigation, the relationship between the viscosity of the defense waste slurry and the temperature has indicated a complicated mechanism.

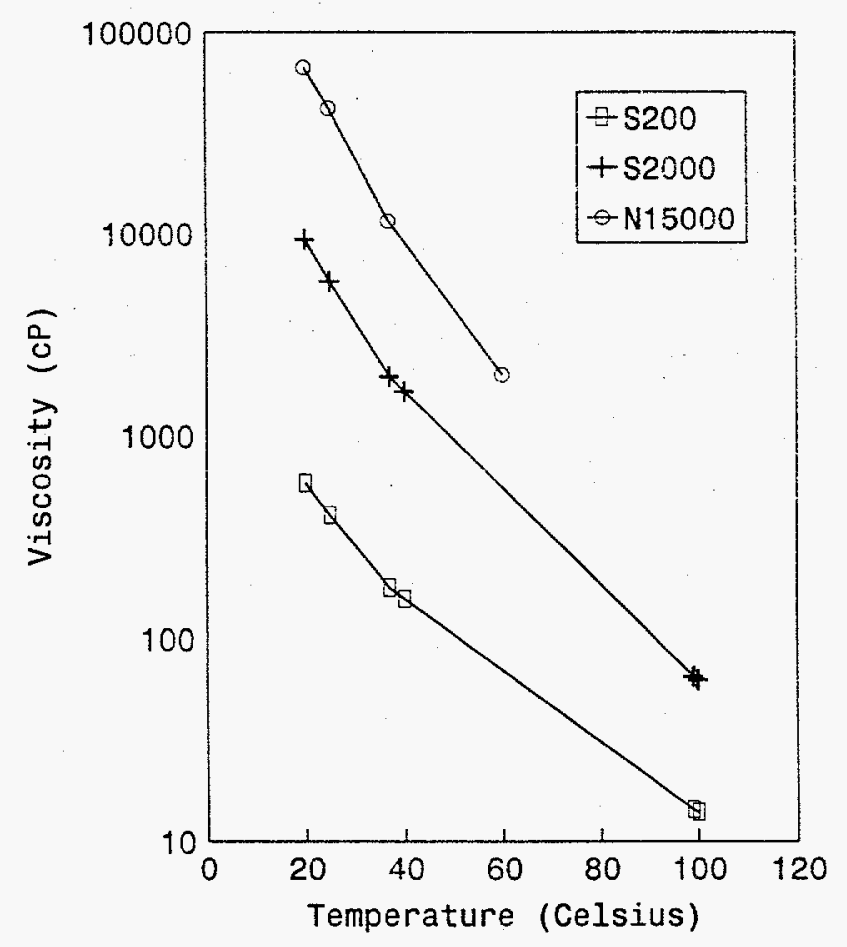

Figure 1. Viscosity of fluid as a function of temperature. 


\section{Concentration of the Solute}

The dependence of the viscosity on the concentration of the solute is usually a direct nonlinear relationship. Figure 2 illustrates the viscosity-concentration behavior of water and sucrose solutions at three concentration levels. It can be observed that at $20^{\circ} \mathrm{C}$, water has a viscosity of 1 $\mathrm{cP}$, while the $60 \%$ sucrose solution has a viscosity of $80 \mathrm{cP}$ at the same temperature. For the slurries tested in this investigation, the effect of the concentration of the solute on the viscosity is indicated by the concentration of the supernate.

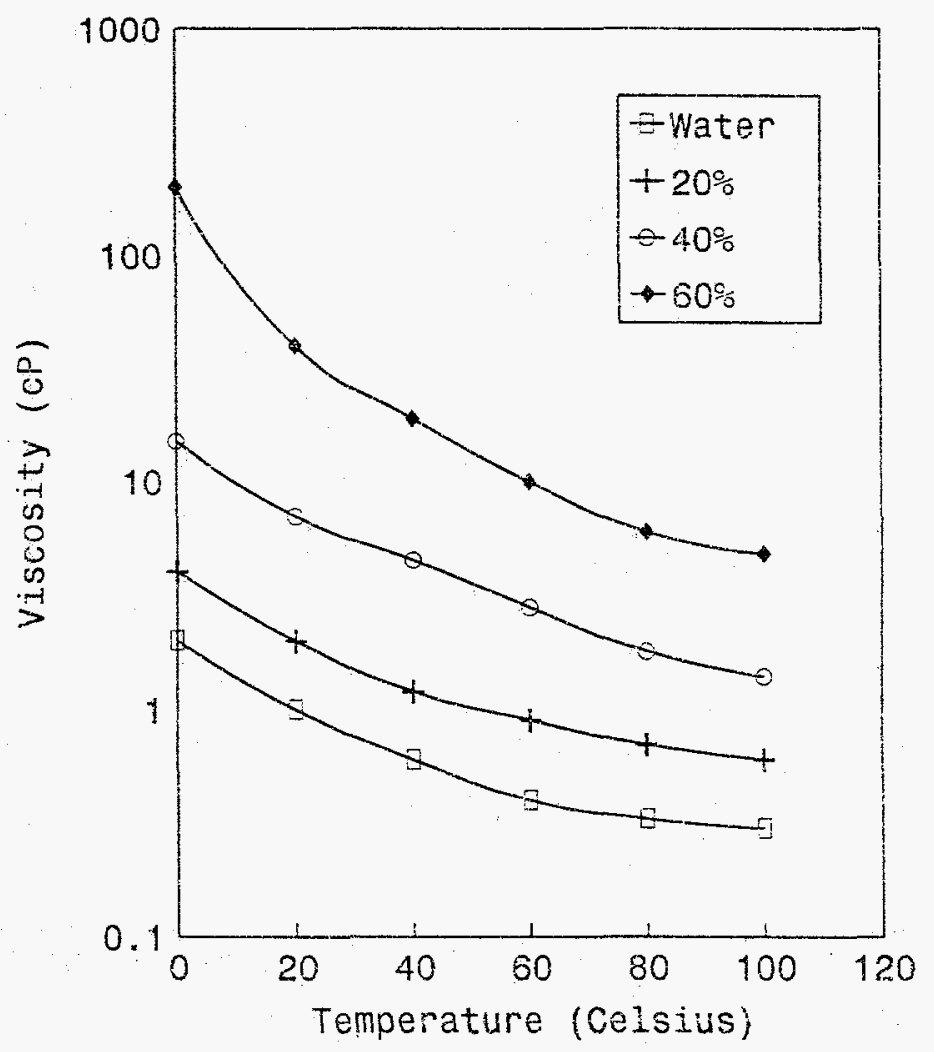

Figure 2. Viscosity of fluid as a function of concentration.

\section{Molecular Weight of the Solute}

A direct nonlinear relationship exists between the molecular weight of the solute and the viscosity of the solution at a constant concentration level. For most organic solutions, a solute with a high molecular weight will significantly increase the viscosity of the solution. The viscosity of inorganic salt solution is slightly dependent on the molecular weight of the salt because these salts are of almost the same molecular size. Since the organic composition of waste slurries is very small, the molecular weight was not examined in this investigation. 


\section{Pressure}

The viscosity of most liquids is essentially constant over a pressure range of 0 to 100 atmospheres. Hence, the effect of pressure on viscosity can usually be ignored for most organic or inorganic solutions.

\section{Suspended Matter}

The presence of suspended materials in a solution usually increases the viscosity slightly when these are in very low concentrations, but high concentrations of suspended matter can cause a substantial increase in viscosity because of the entanglement of the suspended particles. Concentrations of suspended matter usually endow a solution in slurry state with non-Newtonian behavior. In extreme cases, high concentrations of suspended matter can lead to plastic or dilatant flows. In this investigation, it has been found that the concentration of suspended matter has important effects on the viscosity of waste slurries.

The size of the suspended solid particles and the size distribution can affect the viscosity of the slurry. Their effects are indicated by a change in the contact surface of the solid-liquid interface, which plays an important role in the rheology of suspensions. This parameter will be investigated in future work.

This experimental investigation focuses on four parameters that represent the special characteristics of DWPF melter feeds. These parameters include: (1) slurry type, which reflects the chemical nature of the siurry; (2) solids concentration of both insoluble and soluble components; (3) pH value; and (4) temperature. These parameters are those used at the SRS vitrification facility to control the rheology of DWPF melter feeds. Our investigation concerns the rheological properties of specific slurry types under certain parameter ranges.

\subsection{PREVIOUS INVESTIGATIONS}

The slurry transport behavior in a pipeline has been investigated by J. T. Shor, W. Suyatno, R. L. Cummins, and L. L. Farr (1984) in a testing loop using slurry prepared with Kinston fly ash and water. They measured slurry particle size and distribution and the pressure drop as a function of the slurry velocity in a multiple bend testing loop with a 1-in. diameter. Most data from their experiments were obtained by varying slurry concentration and velocity. The data obtained in their investigation were intended to support the design of a proposed waste handling and packaging plant at the Oak Ridge National Laboratory (ORNL).

The rheological properties of a vitrification feed simulant that is used by the DWPF have been measured by the Savannah River Technology Center (SRTC) using a concentric cylindrical rheometer (Marek, 1995). The consistency of the slurry was measured and correlated as a function of the solids concentration. The simulated feed samples used in the experiment contained 25 to 27 weight percent (wt. \%) insoluble solids. The temperature of the slurry was controlled to range between 25 and $50^{\circ} \mathrm{C}$, and no temperature effects were reported. The $\mathrm{pH}$ of the slurry was kept at a constant, and the viscosity was measured under shear rates of 10 to 200 $\mathrm{L} / \mathrm{s}$. The experimental observations were correlated by a Bingham plastic model with estimated 
parameters in the equation. Although the results reported were obtained using limited operating parameters, they serve as a helpful reference and guide for the present investigation.

A review of the research on multiphase pressure drop reveals that many studies have been conducted regarding two-phase (gas/liquid and solid/liquid) flow systems. For instance, the rheology of a coal slurry was studied by Round and Hessari (1987), who examined the effects of slurry $\mathrm{pH}$ and solid particle size distribution on the shear stress of water- and oil-based slurry using a Haake RV12 viscometer. Sellgren (1987) studied the effect of temperature on pressure drop and determined viscosity using a tube viscometer (diameter $=0.5 \mathrm{~cm}$ ). Temperaturedependent changes in rheological properties were evaluated for clay, coal, and iron ore slurries in the low temperature range of 0.5 to $20^{\circ} \mathrm{C}$. Much higher shear stress was observed when the temperature of the slurry approximated $0.5^{\circ} \mathrm{C}$.

Bouzaiene and Hassani (1992) reviewed and classified the pressure drop prediction methods reported in the literature. Several methods were examined using available data from literature on multiphase flow. For other types of multiphase phase flow systems, Lahey et al. (1992) tested global volumetric phase fraction in a horizontal multiphase flows of gas, water, and oil. A detailed set of phasic volume fraction data was measured in a $183-\mathrm{cm}-$ long test loop for the various flow regimes. The resulting data were then correlated with generalized mathematical expressions. Unfortunately, no pressure drop measurements or correlations were reported by the researchers. Kasturi and Stepanek (1972a; 1972b) made a comprehensive study of the multiphase flow of air/corn/sugar/water and air/glycerol/water solutions in a helical coil. Their investigation was limited to the influence of liquid properties and flow rates on void fraction and pressure drop. They treated the multiphase phase flow as a two-phase system composed of gas and a uniform solution. The experimental results were correlated using the Lockhart-Martinelii method.

As pressure drop and correlations for multi-phase flow of nuclear wastes have not been widely investigated, the present study aims to shed light on the complicated solid-liquid phase flow system and provide basic rheological data for the design of pump and pipeline systems to be used in nuclear waste treatment processes. 


\subsection{EXPERIMENTAL SETUP AND SAMPLE PREPARATION}

To provide more information of the rheological property of the slurry under different operating conditions, the experimental design for measuring the rheological properties of vitrification melter feeds presents two options. The first option consists of a batch system using a concentric cylinder viscometer. This experimental setup is used to measure the viscosity of slurries using a small amount of slurry in a glass beaker. The second option is a pipeline flow system that allows the slurry to flow continuously inside the pipeline. The viscosity of the slurry is obtained from the measurements of the pressure drop along the test loop.

\subsection{BATCH OPERATION MODE: CONCENTRIC CYLINDER VISCOMETER}

The concentric cylinder viscometer rotates a sensing element in the slurry and measures the torque necessary to overcome the viscous resistance to the induced movement. This is accomplished by driving the immersed element, which is referred to as a spindle, through a beryllium copper spring via a pivot point assembly. This viscometer is able to measure a wide range of viscosities since viscosity is proportional to the torque windup of the spring connected to the spindle. The spindles of the rheometer and the spindles' speed can be specified according to the solution's viscosity. The percentage of torque applied to the spindle due to the viscosity is related to the fluid's rheological behavior and the constant speed of the spindle.

Because of the unique characteristics of the DWPF melter feeds, this apparatus can only measure the viscosity of slurries at a low shear rate due to the effects of the particles' inertial force on the shear stress when the shear rate is high. The viscometer selected for this investigation, because of its wider operating flexibility, was a Rheology International Shannon Ltd. rheometer model RI1-L. It measures viscosities from 3 to $20,000 \mathrm{cP}$ by using different spindle types and adjusting the spindle speed. The measuring accuracy of this rheometer is $+/-1.0 \%$. The calibration data that were supplied by the manufacturer are shown in Table 1.

Table 1.

Calibration data from (calibration standard: $103 \mathrm{cP} @ 25^{\circ} \mathrm{C}$ )

\begin{tabular}{|r|r|l|}
\hline \multicolumn{1}{|c|}{ Speed (RPM) } & Torque (\%) & \multicolumn{1}{l|}{ Viscosity (cP) } \\
\hline 10 & 16.21 & 98 \\
20 & 33.59 & 101 \\
30 & 50.84 & 102 \\
50 & 85.58 & 102.7 \\
\hline
\end{tabular}

Source: Rheology International Shannon, Ltd. 
Two other viscosity standards have been used to calibrate the viscometer at various operating conditions. The first viscosity standard is the calibration solution provided by Cambridge Applied Systems, Inc. These solutions are Q3E, Q6E, Q20E, and K60, the viscosity of which range from 3 to $100 \mathrm{cP}$ at a temperature of $25^{\circ} \mathrm{C}$

A calibration curve measured using these standard solutions is shown in Figure 3.

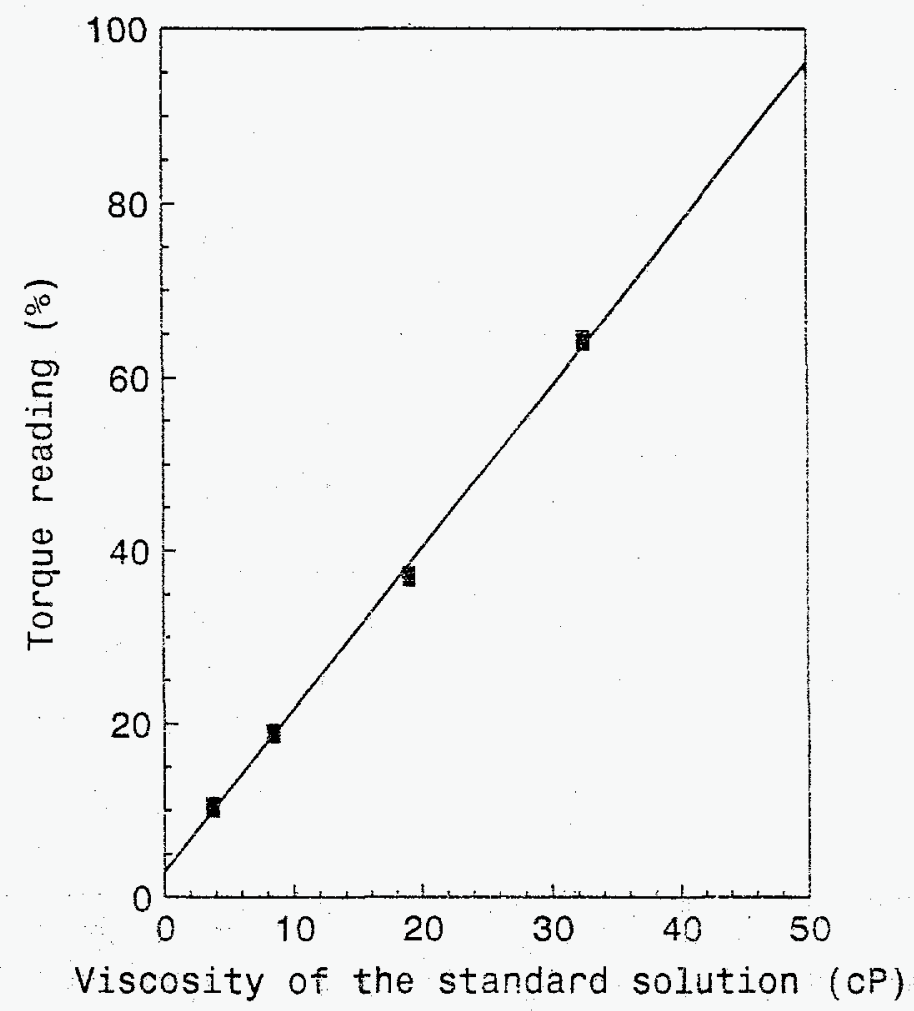

Figure 3. Calibration curve of the rotational viscometer using Fisher Scientific Standards.

When the solids concentration in the slurry was higher than $10 \mathrm{wt} \%$. a viscosity of over $100 \mathrm{cP}$ was measured. To cover the high-concentration measurements in the experiments, the viscometer was also calibrated using high viscosity standards. These standards were provided by Fisher Scientific. The viscosity ranges indicated by Fisher Scientific are listed in Table 2. The temperature dependence for the viscosity of these standards is presented in Figure 1.

Table 2.

Viscosity range of the high viscosity standard

\begin{tabular}{|c|c|c|}
\hline S200 & S2000 & N1500 \\
\hline 14 to $580 \mathrm{cP}$ & 62 to $9332 \mathrm{cP}$ & $2695 \mathrm{cP}$ to $66999 \mathrm{cP}$ \\
\hline
\end{tabular}

Source: Fisher Scientific. 
The viscometer was calibrated using these standards. The calibration data using the highviscosity standards are presented in Tables 3 and 4 . These calibrations were performed at constant temperature of $23^{\circ} \mathrm{C}$ using different spindle types.

Table 3.

Calibration data using high-viscosity standards: $\mathbf{\$ 2 0 0}$

\begin{tabular}{|l|l|l|}
\hline Spindle Speed (RPM) & Torque Reading (Spindle-2) & Torque Reading (Spindle-3) \\
\hline 6 & 8.65 & \\
\hline 10 & 14.4 & 5.31 \\
\hline 12 & 17.5 & 6.0 \\
\hline 20 & 29.5 & 9.53 \\
\hline 30 & 43.6 & 14.3 \\
\hline 50 & 75.5 & 24.5 \\
\hline 60 & 90.6 & 29.5 \\
\hline 100 & over & 49.43 \\
\hline 60 & 90.6 & 29.5 \\
\hline 100 & over & 49.43 \\
\hline
\end{tabular}

Table 4.

Calibration data using high-viscosity standards: $\mathbf{S 2 0 0 0}$

\begin{tabular}{|l|l|l|}
\hline Spindle Speed (RPM) & Torque Reading (Spindle-3) & Torque Reading (Spindle-4) \\
\hline 2.5 & 14.6 & \\
\hline 3 & 17.3 & \\
\hline 5 & 28.7 & 5.7 \\
\hline 6 & 34.6 & 7.0 \\
\hline 10 & 57.3 & 11.7 \\
\hline 12 & 69.9 & 14.1 \\
\hline 20 & Over & 23.5 \\
\hline 30 & Over & 35.2 \\
\hline 50 & Over & 59.2 \\
\hline 60 & Over & 71.5 \\
\hline 100 & Over & Over \\
\hline
\end{tabular}


The concentric spindle rheometer offers the advantage of providing quick and direct output of rheological information at a lower shear rate range using a small amount of sample. The disadvantage is that it is difficult to control uniform concentration in the test vessel when the solids concentration is high. Another concern is that, at a high shear rate, the particle deposition on the outer cylinder surface may affect the accuracy of the measuring results (Marek, 1995).

\subsection{CONTINUOUS OPERATING MODE: PIPELINE FLOW SYSTEM}

To ensure that the slurry was well mixed and to minimize the effect of particle precipitation on the measurement, a pipeline flow system was designed to conduct the experiment at a pilot scale. The rheological properties of the DWPF slurry were obtained from pressure drop measurements along the test tube. A schematic representation of this experimental setup is shown in Figure 4.

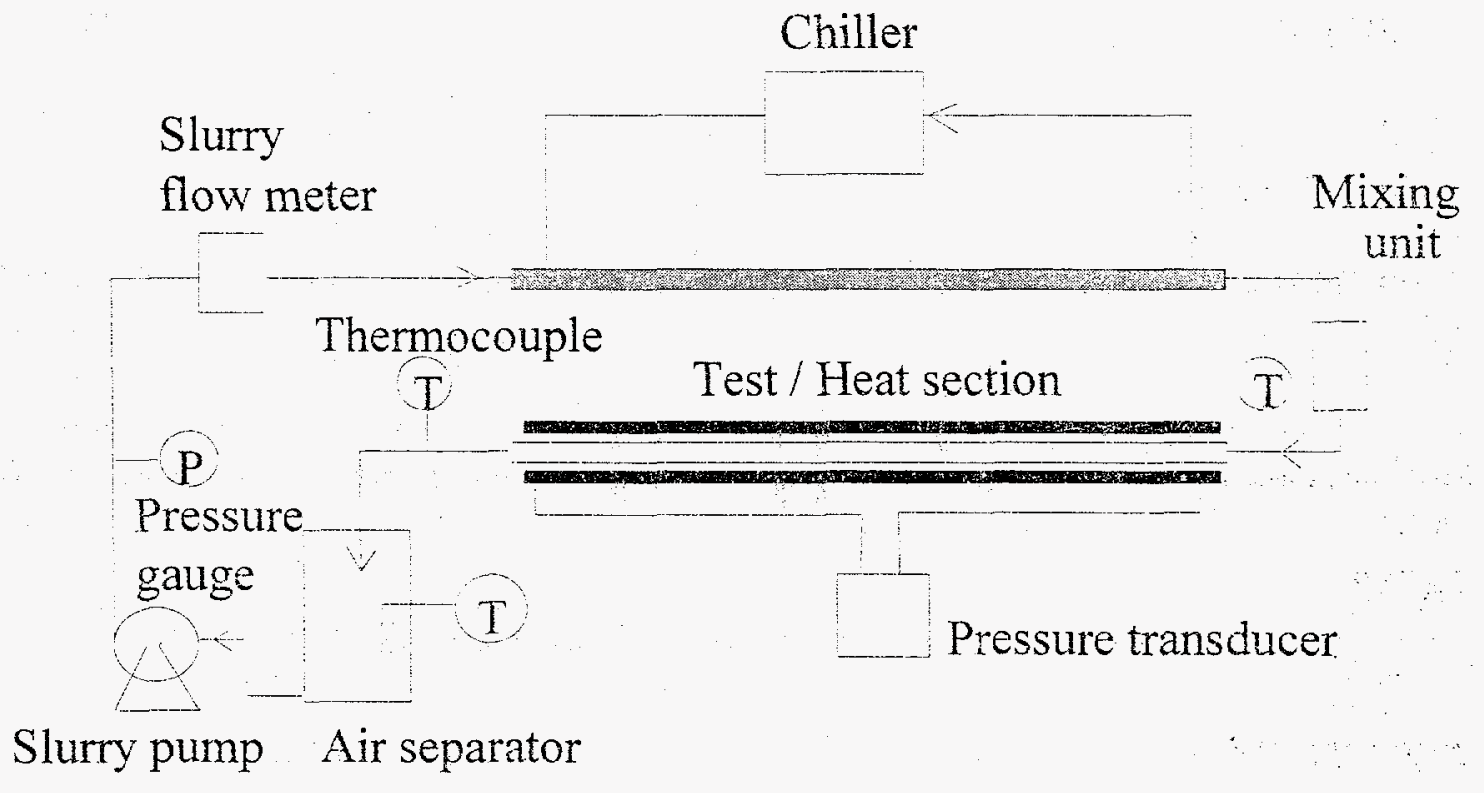

Figure 4. Experimental setup of slurry testing loop.

The DWPF waste slurry was well mixed and prepared at a constant concentration and $\mathrm{pH}$ value before it was loaded into the slurry tank. During the operation, the slurry was pumped out of the mixture reservoir into the pipeline system. It passed through a flow meter and a cooling section into the slurry mixing unit. The two-phase mixture then flowed through a visual section located approximately $30.5 \mathrm{~cm}$ downstream from the mixing unit, entered the test loop, and finally returned to the slurry tank. A pressure gauge was mounted on the outlet of the slurry pump to measure the discharge pressure, and a thermocouple was inserted into the slurry tank to measure the temperature of the slurry. There is a 5-m-long introduction section between the pump and the test loop to eliminate entrance effects and enhance the mixing. 
The test loop consisted of a 2.14-m-long horizontal stainless steel pipe with an inside diameter of $0.025 \mathrm{~m}$. The stainless-steel pipe was electrically heated to maintain the mixture inside the pipe at the specified temperature. Coolant from the chiller flowed through the jacket of the cooling section to adjust the temperature of the slurry inside the test tube. Pressure drop along the test section was measured using a differential pressure transducer (wet-wet) that was routinely calibrated before performing each set of experiments. The reading on the indicator is related to the pressure drop according to the following equation:

$$
\Delta \mathrm{P}=\left(\mathrm{Am}-\mathrm{A}_{0}\right) \mathrm{F}
$$

where $\Delta \mathrm{P}$ denotes the pressure drop (psi), Am represents readings at different slurry flow rates, and $\mathrm{A}_{0}$ is a baseline reading obtained when the fluid velocity in the tube is zero. The term $\mathrm{F}$ is a calibration factor. This kind of pressure drop measurement system has successfully been used to measure the rheological properties of a gibbsite slurry produced by the nitrate to ammonia and ceramic (NAC) process (Ebadian, 1995).

\subsection{EXPERIMENTAL SET UP FOR SETTLING TESTING}

Slurry settling tests under different solids concentrations and $\mathrm{pH}$ levels were conducted after completing the viscosity and pressure drop measurements. A detailed testing procedure was established to guide the settling experiments. The apparatus used for the initial test consisted of $100-\mathrm{mL}$ and $500-\mathrm{mL}$ cylinders. The $100-\mathrm{mL}$ cylinder is shown in Figure 5. An actual test using this apparatus is presented in Figure 6.

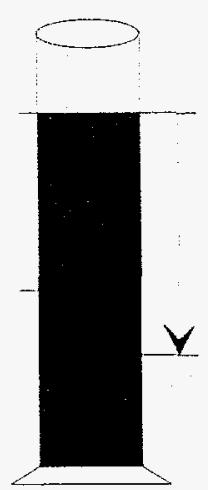

Figure 5. Graduated cylinders used for settling test. 


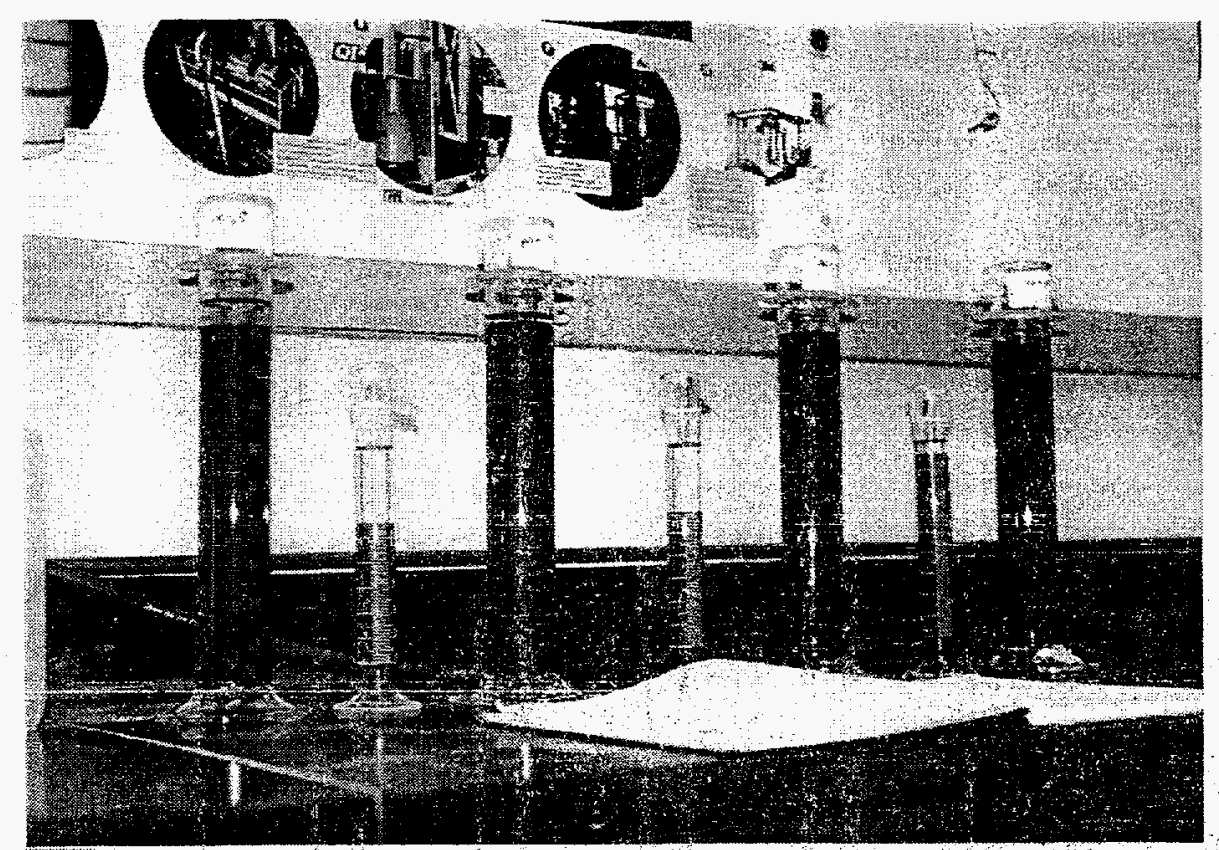

Figure 6. Slurry settling testing in $100 \mathrm{~mL}$ and $500 \mathrm{~mL}$ cylinders.

\subsection{WASTE SLURRY SAMPLE PREPARATION}

The simulated melter feed slurries were supplied by the SRTC. The total volume for each type of simulant was approximately $15 \mathrm{~L}$. The simulants were composed of supernate and concentrated slurry. They were delivered from the DOE site to FIU-HCET in separate plastic containers.

\subsubsection{Sample Analysis}

The sample analysis was conducted by the technical staff at the SRTC for both simulant types. A typical composition of the Savannah River Site slurry is shown in Table 5, while a typical composition of the Hanford slurry is shown in Table 6. In Table 5, the total solids shown include insoluble, soluble, and calcified solids. These metal compositions in the slurry were analyzed using atomic absorption (AA). Other organic/inorganic components were determined by instruments and by wet-chemistry analytical methods. The original $\mathrm{pH}$ of the slurries was determined to be approximately 13 for the SRS slurry and 10 for the Hanford slurry. The soluble salt concentration in the supernate and the insoluble solids concentration in the concentrated slurry were identified using the drying method. The sample was dried in an oven with a controlled temperature of $70^{\circ} \mathrm{C}$. 
Table 5.

Analytical results of SRS sludge (ID\# 32897)

\begin{tabular}{|c|c|c|}
\hline Components & $\begin{array}{c}\text { Concentration (wt \%) } \\
\text { (Dry Basis) }\end{array}$ & Analytical Error (+/- wt. \%) \\
\hline $\mathrm{Al}$ & 6.67 & 0.4 \\
\hline $\mathrm{Ca}$ & 2.67 & 0.15 \\
\hline $\mathrm{Cr}$ & 0.18 & 0.02 \\
\hline $\mathrm{Fe}$ & 26.8 & 1.55 \\
\hline $\mathrm{Mg}$ & 1.31 & 0.08 \\
\hline $\mathrm{K}$ & 0.14 & 0.003 \\
\hline $\mathrm{Mn}$ & 2.8 & 0.16 \\
\hline $\mathrm{Na}$ & 10.2 & 0.6 \\
\hline $\mathrm{Ni}$ & 0.24 & 0.02 \\
\hline $\mathrm{Pb}$ & 0.1 & 0.01 \\
\hline $\mathrm{Si}$ & 0.81 & 0.05 \\
\hline $\mathrm{Zn}$ & 0.17 & 0.01 \\
\hline $\mathrm{SO}_{4}$ & 0.33 & 0.02 \\
\hline $\mathrm{PO}_{4}$ & 0.84 & 0.03 \\
\hline $\mathrm{C}_{2} \mathrm{O}_{4}$ & 0.2 & 0.01 \\
\hline $\mathrm{CO}_{3}$ & 1.94 & 0.1 \\
\hline $\mathrm{NO}_{3}$ & 1.96 & 0.05 \\
\hline $\mathrm{NO}_{2}$ & 5.86 & 0.03 \\
\hline $\mathrm{OH}$ & 2.95 & 0.05 \\
\hline Total organic carbon & $<50 \mathrm{ppm}^{*}$ & \\
\hline Total solids & 26.29 & 0.5 \\
\hline
\end{tabular}

* Parts per million 
Table 6.

Analytical results of the Hanford sludge (ID\# 200053234)

\begin{tabular}{|l|l|l|}
\hline \multicolumn{1}{|c|}{ Components } & \multicolumn{1}{|c|}{ Concentration } & Unit \\
\hline $\mathrm{Al}$ & 6.30 & wt. \% \\
$\mathrm{Ca}$ & 0.448 & wt. \% \\
$\mathrm{Cr}$ & 0.006 & wt. \% \\
$\mathrm{Fe}$ & 27.3 & wt. \% \\
$\mathrm{Mg}$ & 0.193 & wt. \% \\
$\mathrm{K}$ & 0.003 & wt. \% \\
$\mathrm{Mn}$ & 2.22 & wt. \% \\
Na & 1.38 & wt. \% \\
Ni & 2.44 & wt. \% \\
$\mathrm{Pb}$ & $<0.004$ & wt. \% \\
Si & 0.238 & wt. \% \\
Zn & 0.017 & wt. \% \\
Ammonium & $<100$ & $\mathrm{mg} / \mathrm{L} *$ \\
Fluoride & 0.84 & $\mathrm{mg} / \mathrm{L}$ \\
Formate & 0.2 & $\mathrm{mg} / \mathrm{L}$ \\
Chloride & 1.94 & $\mathrm{mg} / \mathrm{L}$ \\
Nitrite & 1.96 & $\mathrm{mg} / \mathrm{L}$ \\
Nitrate & $2.148 \mathrm{E} 3$ & $\mathrm{mg} / \mathrm{L}$ \\
Sulfate & 359 & $\mathrm{mg} / \mathrm{L}$ \\
Total organic carbon & 510 & Ppm \\
Total inorganic carbon & 189 & \\
\hline
\end{tabular}

* Milligrams per liter

** Parts per million 


\subsubsection{Sample Preparation}

A series of samples were prepared at different total solids concentrations by mixing the supernate and the concentrated slurry. Figure 7 shows the relationship between the solids concentration and the ratio of the suspension to the total volume. This diagram can help to estimate the solids concentration based on the volumetric suspension ratio in a well precipitated slurry.

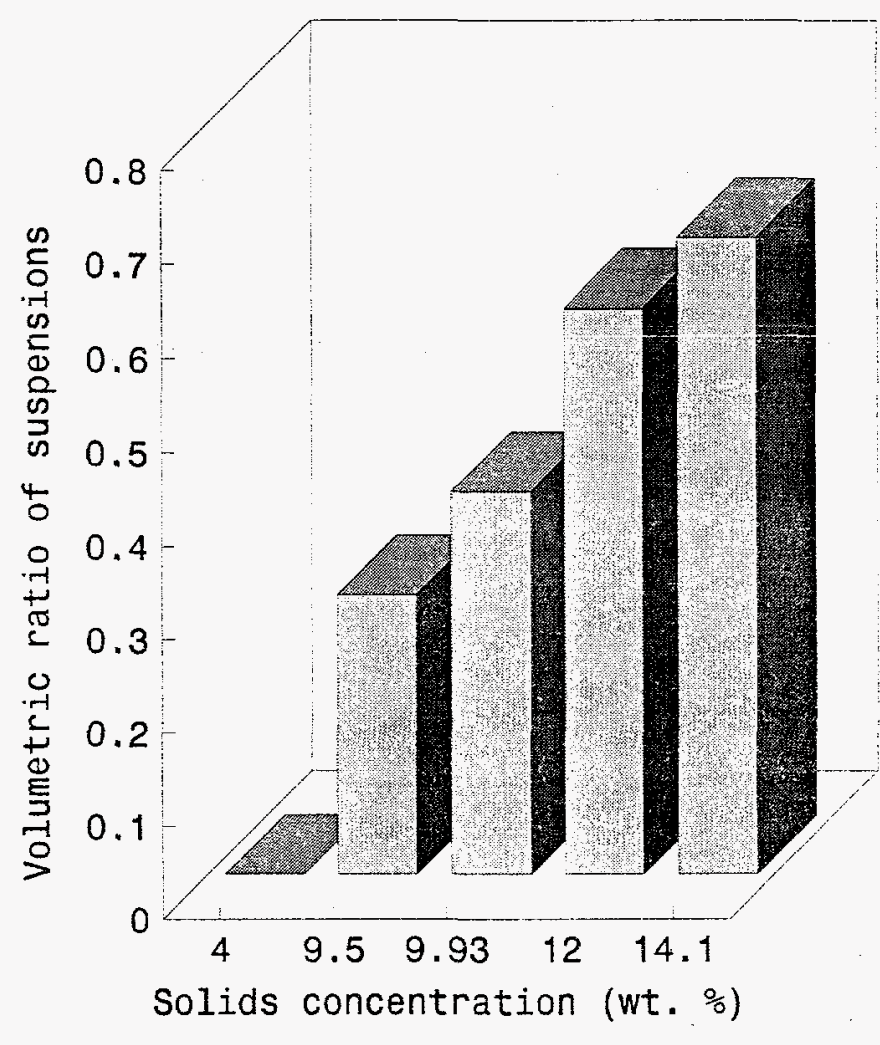

Figure 7. Relationship of solids concentration and settled sludge.

Table 7 shows the concentrations of samples of the SRS and Hanford slurries for initial testing under lower solids concentration ranges. Before using the samples in the rotational viscometer measurement, each sample was mixed thoroughly to obtain a homogeneous mixture. The $\mathrm{pH}$ values of the sample at selected solids concentration were adjusted by the addition of sulfuric acid $\left(\mathrm{H}_{2} \mathrm{SO}_{3}\right)$. To adjust the slurry $\mathrm{pH}$ back to its original value and to check the measurement's consistency while the $\mathrm{pH}$ changed from acidic to basic and back, sodium hydroxide $(\mathrm{NaOH})$ was also used to increase the $\mathrm{pH}$ of the slurry. For each well-mixed sample, the $\mathrm{pH}$ value was measured using $\mathrm{AgCl} /$ reference electrodes and a digital $\mathrm{pH}$ meter. 
Table 7.

Prepared sample concentrations

\begin{tabular}{|l|l|l|}
\hline \multicolumn{1}{|c|}{ Sample } & \multicolumn{1}{|c|}{$\begin{array}{c}\text { Concentration (wt. \%) } \\
\text { SRS Slurry }\end{array}$} & $\begin{array}{c}\text { Concentration (wt. \%) } \\
\text { Hanford Slurry }\end{array}$ \\
\hline 1 & 5.5 & 5.7 \\
\hline 2 & 9.5 & 7.6 \\
\hline 3 & 12 & 9.3 \\
\hline 4 & 9.9 & 11.5 \\
\hline 5 & 14.1 & 15.0 \\
\hline
\end{tabular}




\subsection{EXPERIMENTAL STUDY USING A ROTATIONAL VISCOMETER}

For both the SRS and Hanford slurries, investigations were conducted with five solids concentrations. Nine temperature points and ten $\mathrm{pH}$ levels were examined under a specified solids concentration.

\subsection{MEASUREMENT METHOD}

The concentric rotational rheometer offers the advantage of providing quick and direct output of rheological information at a certain shear rate range. The disadvantage is that it is difficult to control uniform concentration and temperature in the test vessel when the solids concentration is high. To enhance the concentration's uniformity inside the test beaker, the slurry was well mixed before the spindle was inserted. The temperature gradient was minimized by heating the sample beaker in a water bath and measuring the slurry temperature at different points along the radius direction until the same temperature reading was obtained.

\subsection{PARAMETRIC INVESTIGATIONS}

The slurry types used for testing were the SRS and Hanford slurries. For each, the following parameters have been investigated: solids concentration, $\mathrm{pH}$, and temperature.

\subsubsection{Effect of the Concentration of Solids}

For each simulant, five samples were prepared at different total solids concentration levels by mixing the supernate and the concentrated slurry. The details of the solids concentration are shown in Table 7. Before measurement, each sample was loaded into a $400 \mathrm{ml}$ glass beaker and mixed thoroughly to obtain a homogeneous mixture. The viscometer was set up at the "autozero" option, and the spindle was run in air to obtain a reading of zero before the spindle was inserted into the sample beaker. The measured viscosity of the slurries and its dependency on the solids concentration are shown in Figures 8 through 11. The results obtained regarding the SRS slurry are presented in Figures 8 and 9, and those for the Hanford slurry are presented in Figures 10 and 11 . 


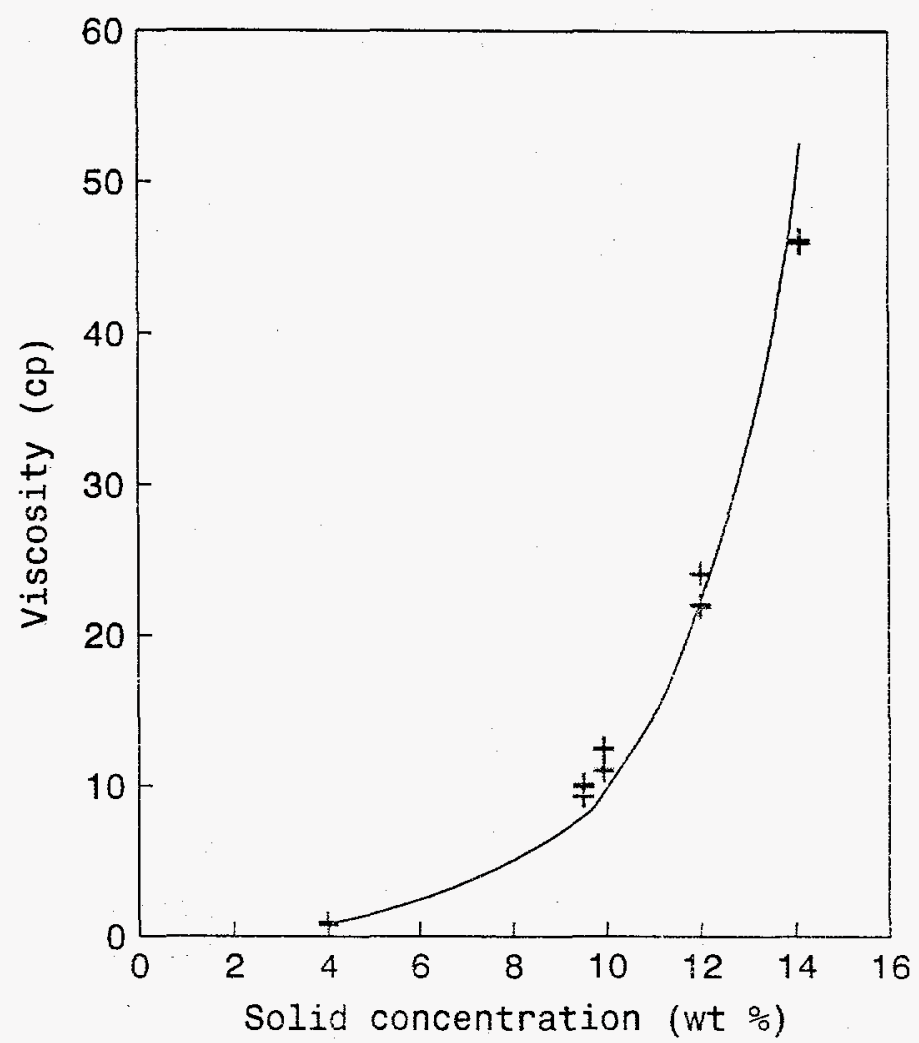

Figure 8. SRS slurry viscosity as a function of solids concentration.

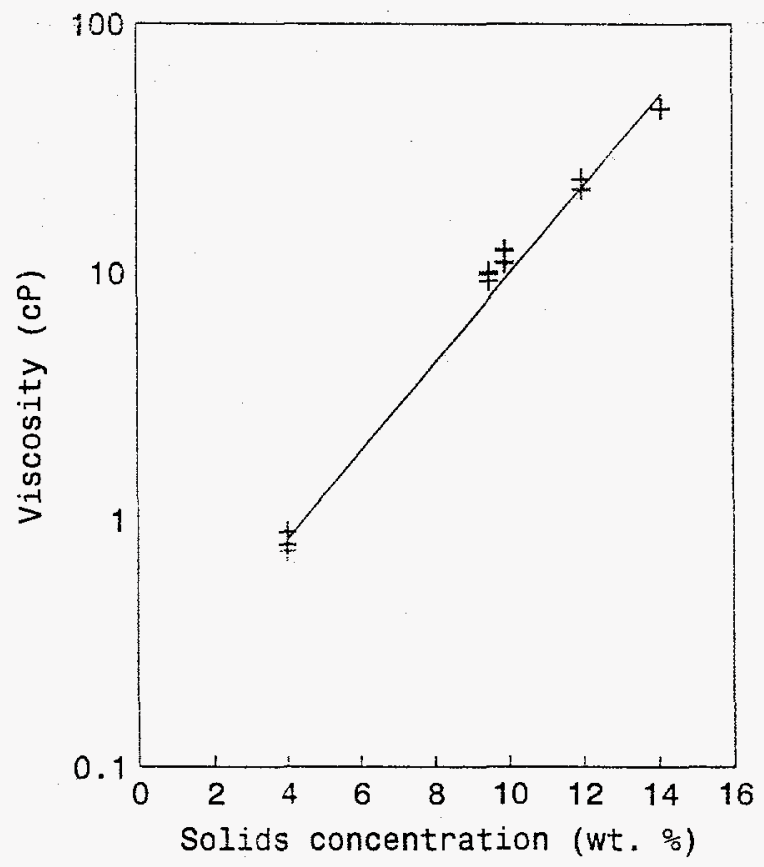

Figure 9. SRS slurry viscosity (in log scale) as a function of solids concentration. 


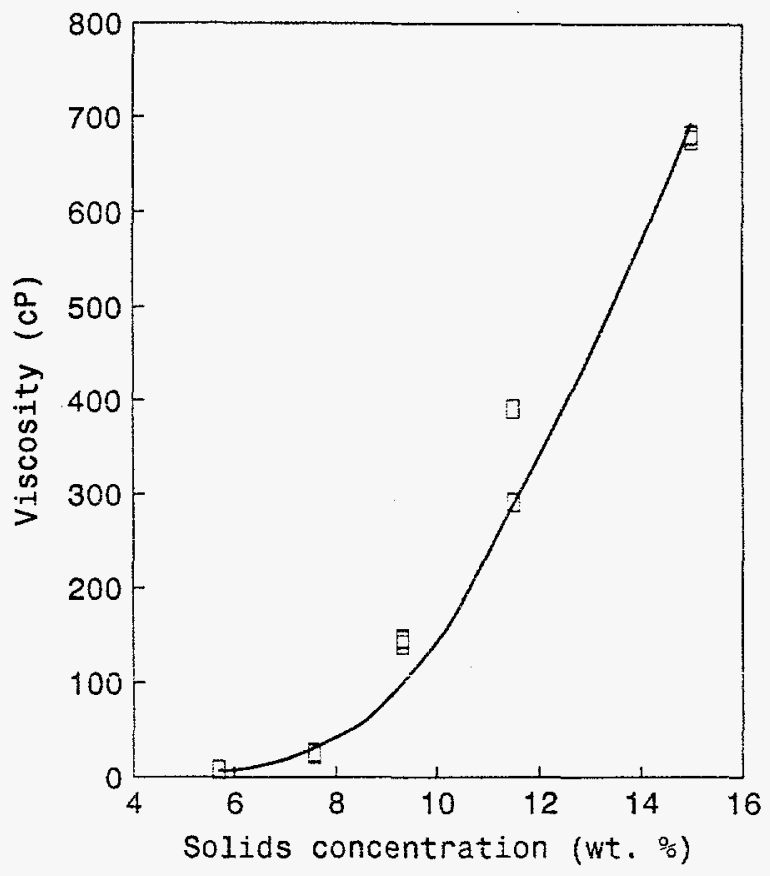

Figure 10. Hanford slurry viscosity as a function of solids concentration.

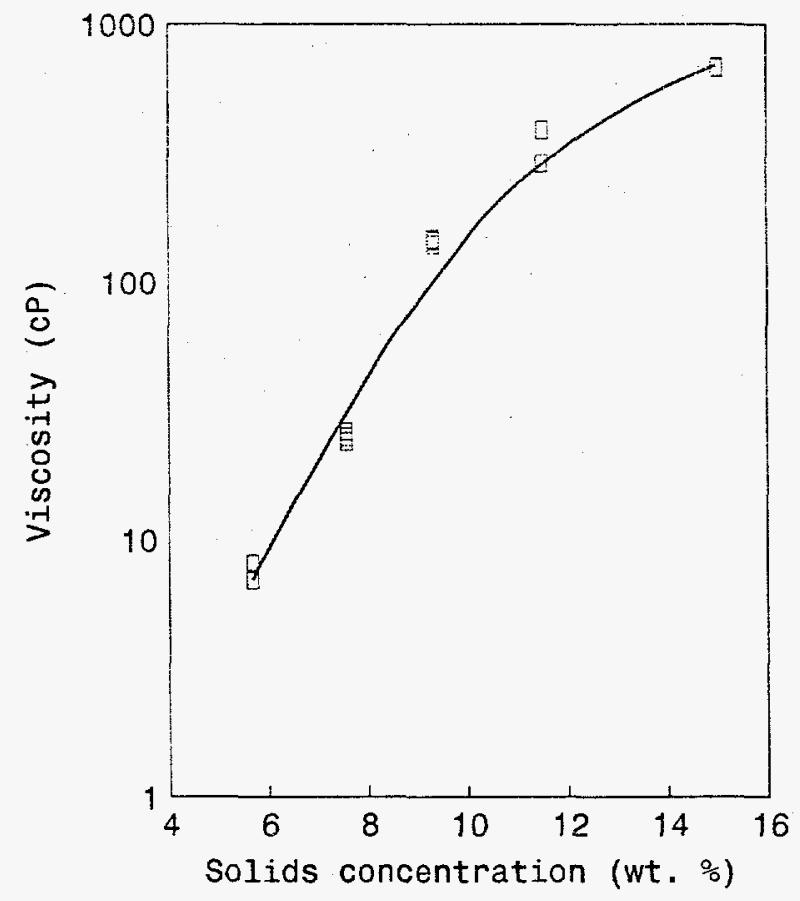

Figure 11. Hanford slurry viscosity (in log scale) as a function of solids concentration. 


\subsubsection{Effects of the pH on the Slurry Viscosity}

The $\mathrm{pH}$ values of the slurry at selected solids concentration were adjusted by the addition of sulfuric acid $\left(\mathrm{H}_{2} \mathrm{SO}_{3}\right)$. To adjust the slurry $\mathrm{pH}$ back to its original value, sodium hydroxide $(\mathrm{NaOH})$ was used. The $\mathrm{pH}$ value of the slurry was measured using $\mathrm{AgCl} /$ reference electrodes and a digital $\mathrm{pH}$ meter. For the specified concentrations of both slurries, the $\mathrm{pH}$ was adjusted at several levels from a minimum of 4 to a maximum of 13.5. During the addition of sulfuric acid $\left(\mathrm{H}_{2} \mathrm{SO}_{3}\right)$, chemical reaction heat was released, and the temperature of the slurry was increased. To keep the temperature at a constant, the reaction heat was removed by placing the sample tank in a cold-water bath. When the temperature reached the specified value, the measurement began. The volumetric effect due to the addition of liquid acid and a solid base will be discussed in the results discussion section. Table 8 lists these $\mathrm{pH}$ value changes following the addition of sulfuric acid $\left(\mathrm{H}_{2} \mathrm{SO}_{3}\right)$ and sodium hydroxide $(\mathrm{NaOH})$. The arrows in the table indicate the $\mathrm{pH}$ 's changing direction. The effect of $\mathrm{pH}$ on the viscosity of both the SRS and Hanford slurries at lower concentration are shown in Figures 12 and 13.

Table 8 .

pH value adjusted with $\mathrm{H}_{2} \mathrm{SO}_{4}$ and $\mathrm{NaOH}$

\begin{tabular}{|l|l|l|l|l|l|l|l|l|l|l|}
\hline \multicolumn{2}{|l|}{$\mathrm{H}_{2} \mathrm{SO}_{4}$ Addition } & \multicolumn{10}{l|}{} & \\
\hline $\mathrm{pH}$ & 12.94 & 8.62 & 8.56 & 8.45 & 6.45 & 6.08 & 5.65 & 5.29 & 4.58 & 4.27 \\
\hline $\mathrm{NaOH}$ Addition & \\
\hline $\mathrm{pH}$ & 12.95 & 11.77 & 9.85 & 9.61 & 9.0 & 8.45 & 7.08 & 5.99 & 5.03 & 4.27 \\
\hline
\end{tabular}




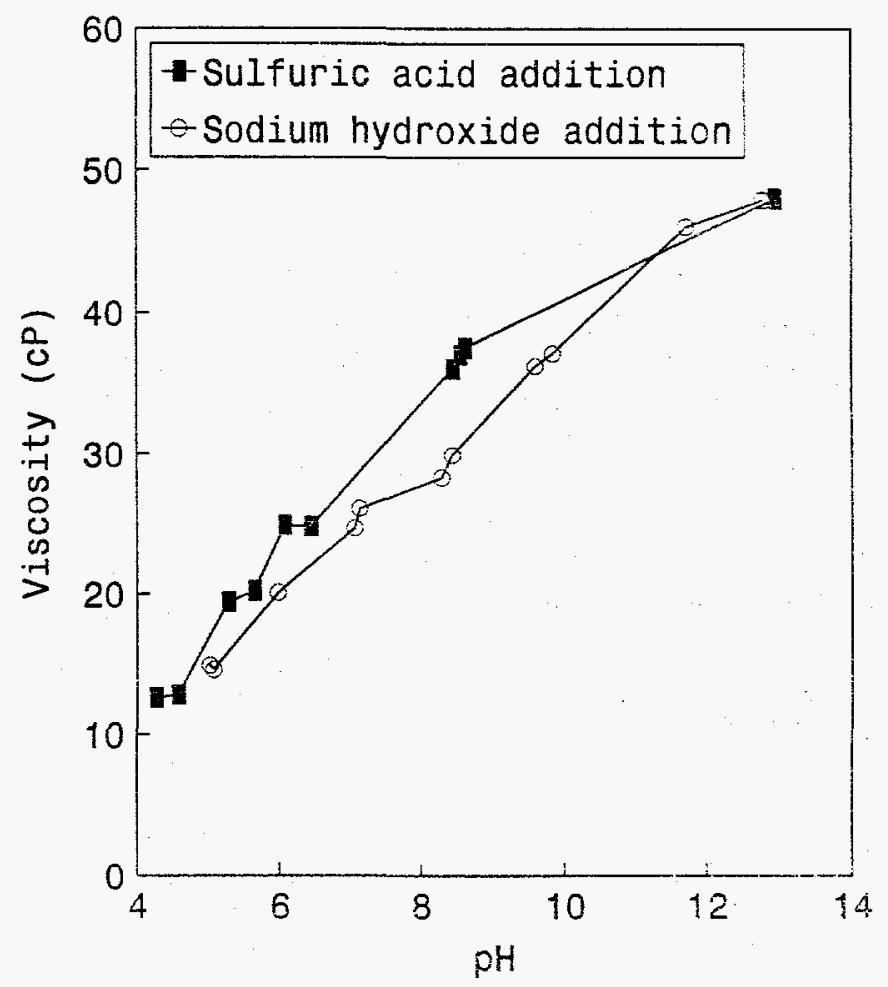

Figure 12. Effect of pH on the viscosity of the SRS slurry. 


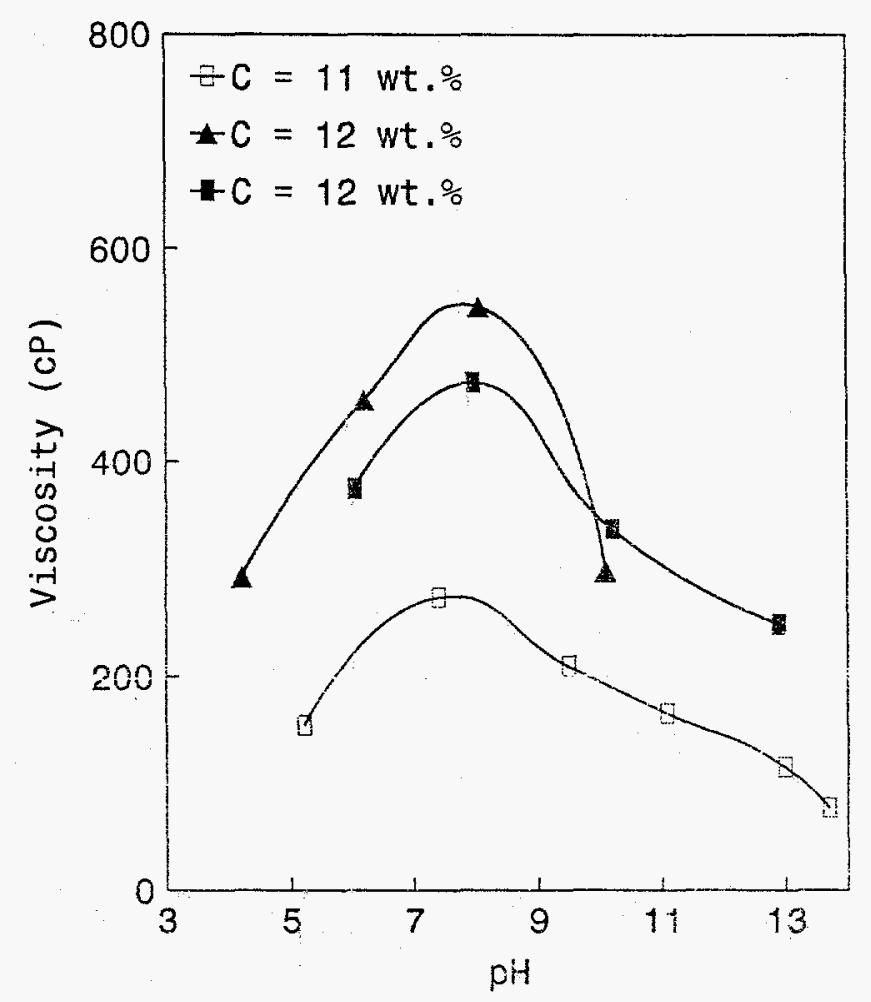

Figure 13. Effect of pH on the viscosity of the Hanford slurry the pH was adjusted by sulfuric acid for the upper and lower curves and by sodium hydroxide for the middle curve).

The data analysis of $\mathrm{pH}$ effect on the slurry viscosity at higher solids concentrations has been performed for both the Hanford and SRS slurries. The experimental results for the Hanford slurry (solids concentration $=16 \%$ by weight) and SRS slurry (solids concentration $=25 \%$ by weight) have been shown in Tables 9 and 10. The measurements were performed at a constant temperature of $24^{\circ} \mathrm{C}$. The $\mathrm{pH}$ ranges in which the experiments were conducted were 5.31 to 12.13 for the Hanford slurry and 5.83 to 10.40 for the SRS slurry. 
Table 9.

$\mathrm{pH}$ effect on the viscosity of the SRS slurry

(Readings were taken at given time intervals; Temperature $=24^{\circ} \mathrm{C}$ )

\begin{tabular}{|l|l|l|l|l|l|l|}
\hline $\mathrm{pH}$ & $\begin{array}{l}\text { Spindle Speed } \\
(\mathrm{RPM})\end{array}$ & 2 minutes & 4 minutes & 6 minutes & 8 minutes & 10 minutes \\
\hline \multirow{3}{*}{10.40} & 10 & 41.46 & 43.81 & 45.65 & 42.03 & 48.34 \\
\hline \multirow{3}{*}{8.02} & 12 & 27.15 & 27.75 & 24.78 & 25.71 & 27.18 \\
\hline & 12 & 78.59 & 77.76 & 77.18 & 76.21 & 75.43 \\
& 10 & 65.56 & 63.65 & 62.06 & 61.15 & 60.40 \\
\hline \multirow{5}{*}{6.15} & 30 & 54.43 & 52.96 & 53.18 & 50.90 & 50.37 \\
\hline \multirow{3}{*}{5.83} & 20 & 54.56 & 52.43 & 49.15 & 48.03 & 47.09 \\
\hline
\end{tabular}

Table 10.

pH effect on the viscosity of the Hanford slurry

(Readings were taken at given time intervals; Temperature $=24^{\circ} \mathrm{C}$ )

\begin{tabular}{|l|l|l|l|l|l|l|}
\hline $\mathrm{pH}$ & $\begin{array}{l}\text { Spindle Speed } \\
\text { (RPM) }\end{array}$ & 2 minutes & 4 minutes & 6 minutes & 8 minutes & 10 minutes \\
\hline \multirow{2}{*}{12.13} & 12 & 62.28 & 55.93 & 54.65 & 53.53 & 52.63 \\
\hline 10.28 & 10 & 46.81 & 45.62 & 45.71 & 45.53 & 45.71 \\
& 12 & 66.65 & 63.15 & 62.40 & 62.34 & 61.93 \\
\hline \multirow{3}{*}{7.25} & 12 & 52.18 & 52.56 & 52.81 & 52.15 & 52.62 \\
& 10 & 62.28 & 61.09 & 57.21 & 54.4 & 49.81 \\
& 6 & 36.59 & 36.34 & 35.9 & 34.9 & 33.65 \\
\hline \multirow{3}{*}{5.31} & 30 & 19.03 & 19.46 & 20.56 & 21.68 & 20.34 \\
& 20 & 79.93 & 78.09 & 77.31 & 76.09 & 74.9 \\
& 12 & 64.53 & 63.03 & 60.00 & 58.43 & 57.28 \\
& & 48.81 & 48.59 & 48.37 & 48.28 & 48.00 \\
\hline
\end{tabular}




\subsubsection{Effects of Temperature}

The temperature effect on the viscosity of the slurry has been investigated from room temperature to the maximum slurry operating temperature, $66^{\circ} \mathrm{C}$. The temperature was maintained at less than $66^{\circ} \mathrm{C}$ to avoid chemical reactions in the slurry at high temperatures and water evaporation from the slurry. In both of these cases, the compesition and concentration of the slurry would be influenced. The temperature of the slurry was raised from $25^{\circ} \mathrm{C}$ to $66^{\circ} \mathrm{C}$ using a Fisher Scientific water bath. At each temperature level, enough heating time was allowed to ensure a thermal equilibrium was reached in the slurry.

At a lower concentration range, the effect of temperature was examined for two concentrations of the SRS slurry and for one concentration of the Hanford slurry. Experimental observations are presented in Figures 14 and 15.

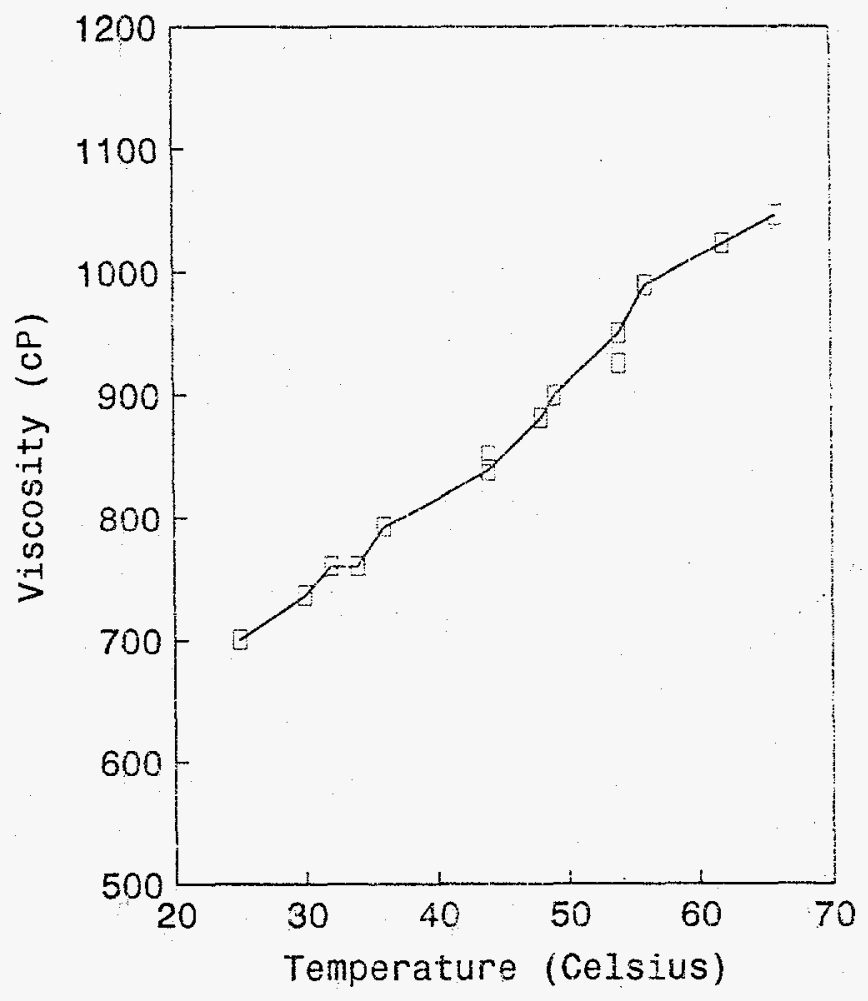

Figure 14. Effect of temperature on SRS slurry viscosity (Solids concentration, $15 \mathrm{wt}$. \%). 


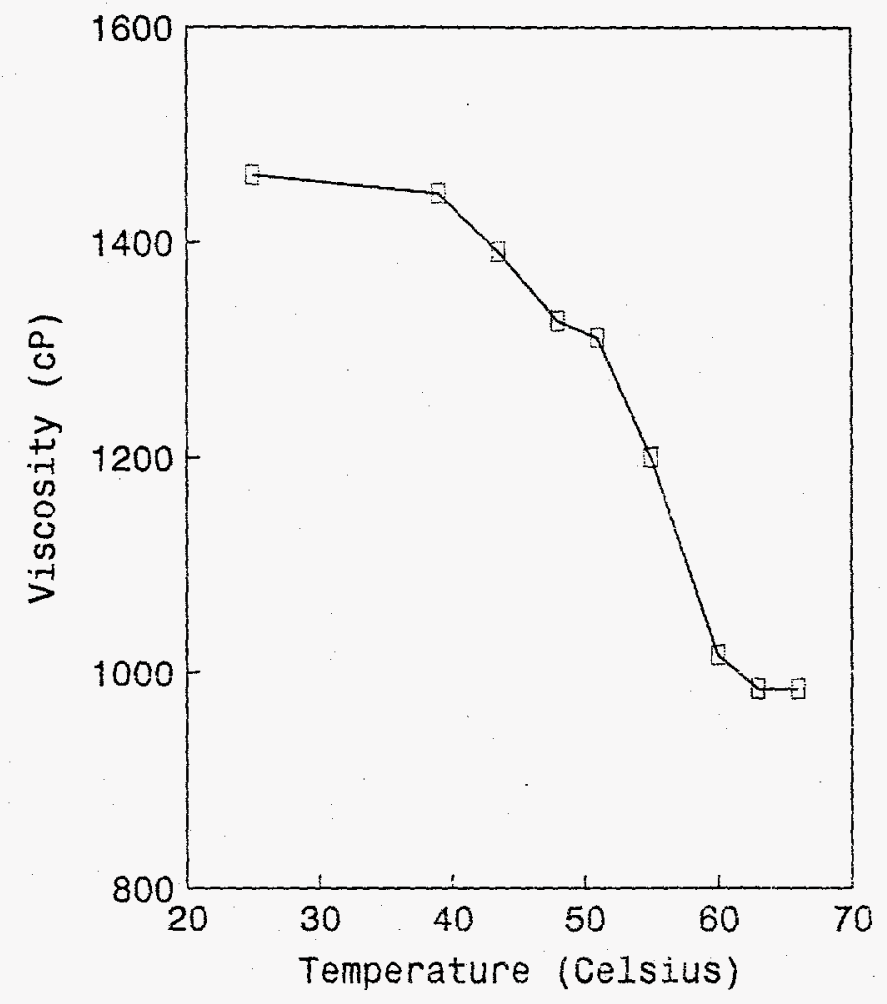

Figure 15. Effect of temperature on SRS slurry viscosity (Solids concentration, $17 \mathrm{wt} . \%$ ).

The results of testing the Hanford slurry are shown in Figure 16. All temperature effect experiments were conducted under constant $\mathrm{pH}$ and viscometer operating conditions. Unlike other regular fluids that have consistent temperature dependencies, the DWPF melter feed simulants showed quite different temperature-viscosity relationships at different concentrations levels. For example, at a concentration of $15 \mathrm{wt} . \%$, the viscosity of the SRS slurry increased as the temperature increased, but it decreased as the temperature increased when the concentration was higher than $17 \mathrm{wt} \%$. On the other hand, for the Hanford slurry at a concentration of $12 \mathrm{wt} . \%$, the viscosity increased when the temperature increased. 


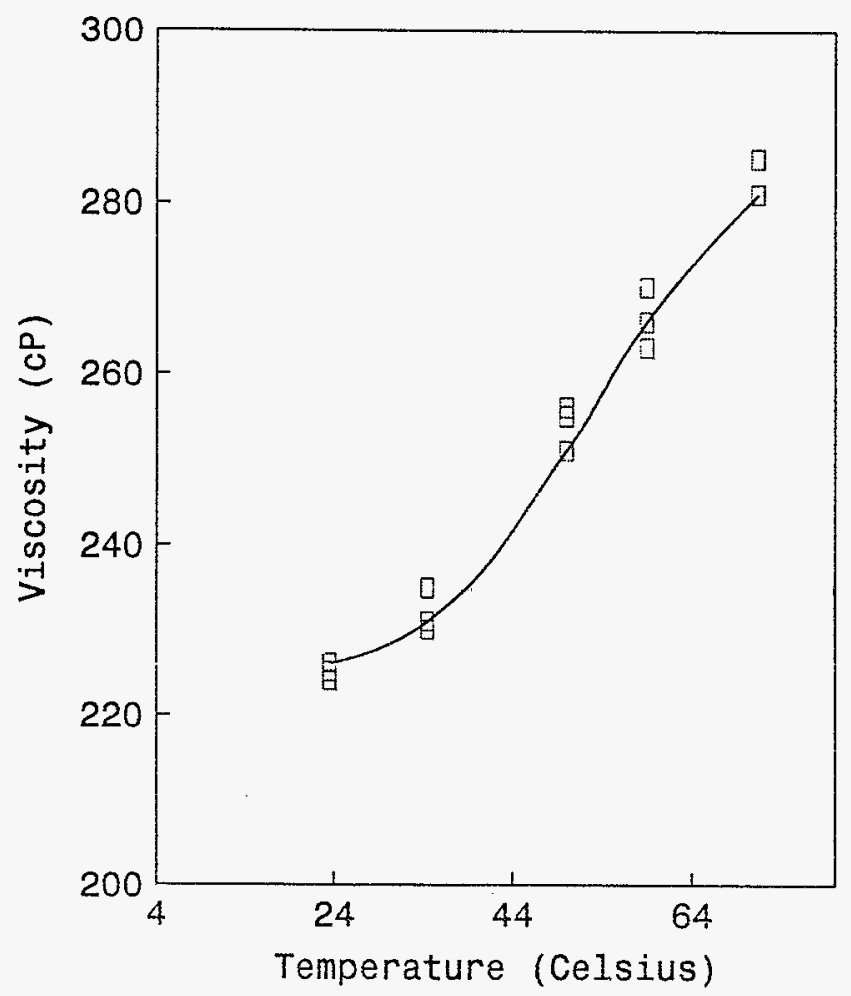

Figure 16. Effect of temperature on the viscosity of the Hanford slurry.

Samples for both SRS and Hanford slurries have been prepared at higher solids concentrations of 25 wt.\% (SRS) and 17 wt. \% (Hanford). The solids concentrations were measured using the drying method and were calculated by the following equation:

$$
C_{s}=\frac{W_{\text {grows }}-W_{\text {seaker }}}{W_{\text {dry }}-W_{\text {becker }}}
$$

where $\mathrm{W}_{\text {gross }}$ is the total weight of beaker and wet slurry, $\mathrm{W}_{\text {beaker }}$ is the weight of beaker that contained the slurry sample, and $\mathrm{W}_{\mathrm{dry}}$ is the weight of the dried slurry and the beaker.

Temperature effects on the slurry viscosity at the higher solids concentrations were investigated using a rotational viscometer. The experimental results for the Hanford slurry $(\mathrm{pH}=10)$ showed that the slurry viscosity does not change much when the temperature was raised from 23 to $70^{\circ} \mathrm{C}$. (Tables 11 to 14). On the other hand, the observations from the measurement of the SRS slurry $(\mathrm{pH}=8.5)$ indicated that the slurry viscosity increased as the temperature increased from 30 to $50^{\circ} \mathrm{C}$ and then decreased as the temperature increased from 50 to $70^{\circ} \mathrm{C}$. (Tables 15 to 17). Data listed in these tables have been plotted in Figures 17 to 20 to show the relationship of slurry viscosity with the temperature. 
Table 11.

Temperature effect on the viscosity of Hanford slurry (Solids Concentration $=17 \mathrm{wt}$. $\%$; $\mathrm{pH}=10$; Temperature $=23^{\circ} \mathrm{C}$ )

\begin{tabular}{|c|c|c|c|c|c|c|c|c|c|}
\hline & & \multicolumn{6}{|c|}{ Readings (Engineering Unit) at different time (minutes) } \\
\hline Spindle \# & Speed (RPM) & 2 & 4 & 6 & 8 & 10 & 12 & 14 & 16 \\
\hline 3 & 20 & 74.96 & 74.50 & 74.09 & 73.43 & 72.89 & 72.28 & 71.25 & 70.59 \\
\hline 4 & 100 & 25.93 & 24.40 & 23.37 & 22.37 & 21.37 & 20.73 & 19.37 & 18.84 \\
\hline
\end{tabular}

Table 12.

Temperature effect on the viscosity of Hanford slurry (Solids Concentration=17 wt. \%; $\mathrm{pH}=10 ;$ Temperature $=30^{\circ} \mathrm{C}$ )

\begin{tabular}{|c|c|c|c|c|c|c|}
\hline & & \multicolumn{4}{|c|}{ Readings (Engineering Unit) at different time (minutes) } \\
\hline Spindle \# & Speed (RPM) & 5 & 10 & 15 & 20 & 25 \\
\hline 3 & 30 & 67.7 & 66.1 & 65.9 & 64.0 & 64.9 \\
\hline 3 & 50 & 77.5 & 73.7 & 72.6 & 71.8 & 72.3 \\
\hline 3 & 60 & 78.6 & 72.9 & 70.4 & 68.6 & 67.7 \\
\hline
\end{tabular}

Table 13.

Temperature effect on the viscosity of Hanford slurry (Solids Concentration $=17$ wt. $\% ; \mathrm{pH}=10 ;$ Temperature $=50^{\circ} \mathrm{C}$ )

\begin{tabular}{|c|c|c|c|c|c|c|}
\hline & & \multicolumn{4}{|c|}{ Readings (Engineering Unit) at different time (minutes) } \\
\hline Spindle \# & Speed (RPM) & 5 & 10 & 15 & 20 & 25 \\
\hline 3 & 20 & 62.1 & 60.9 & 61.9 & 61.5 & 63.0 \\
\hline 3 & 30 & 69.4 & 70.3 & 70.4 & 70.6 & 70.8 \\
\hline 3 & 50 & 73.3 & 72.3 & 70.8 & 68.8 & 65.1 \\
\hline
\end{tabular}


Table 14.

Temperature effect on the viscosity of Hanford slurry (Solids concentration $=17$ wt. $\% ; \mathrm{pH}=10 ;$ Temperature $=70^{\circ} \mathrm{C}$ )

\begin{tabular}{|c|c|c|c|c|c|c|}
\hline & & \multicolumn{5}{|c|}{ Readings (Engineering Unit) at different time (minutes) } \\
\hline Spindle \# & Speed (RPM) & 5 & 10 & 15 & 20 & 25 \\
\hline 3 & 30 & 75.9 & 76.1 & 75.8 & 75.3 & 76.3 \\
\hline 3 & 50 & 80.7 & 79.8 & 78.2 & 77.6 & 76.0 \\
\hline
\end{tabular}

Table 15.

Temperature effect on the viscosity of SRS slurry

(Solids concentration $=25 \mathrm{Wt} . \% ; \rho H=8.6$; Temperature $=30^{\circ} \mathrm{C}$ )

\begin{tabular}{|c|c|c|c|c|c|c|}
\hline & & \multicolumn{5}{|c|}{ Readings (Engineering Unit) at different time (minutes) } \\
\hline Spindle \# & Speed (RPM) & 5 & 10 & 15 & 20 & 25 \\
\hline 3 & 12 & 49.9 & 46.4 & 40.7 & 34.0 & 29.9 \\
\hline 3 & 20 & 65.5 & 64.4 & 43.3 & 60.2 & 56.4 \\
\hline 3 & 30 & 92.3 & 78.9 & 76.9 & 74.7 & 72.8 \\
\hline
\end{tabular}

Table 16.

Temperature effect on the viscosity of SRS slurry

(Solids concentration $=25 \mathrm{wt} . \% ; \mathrm{pH}=8.6 ;$ Temperature $=50^{\circ} \mathrm{C}$ )

\begin{tabular}{|c|c|c|c|c|c|c|}
\hline & & \multicolumn{5}{|c|}{ Readings (Engineering Unit) at different time (minutes) } \\
\hline Spindle \# & Speed (RPM) & 5 & 10 & 15 & 20 & 25 \\
\hline 3 & 12 & 37.3 & 35.9 & 36.4 & 33.9 & 34.5 \\
\hline 3 & 20 & 67.8 & 68.9 & 68.2 & 67.4 & 66.7 \\
\hline 3 & 30 & 81.3 & 77.4 & 75.9 & 74.5 & 73.2 \\
\hline
\end{tabular}


Table 17.

Temperature effect on the viscosity of SRS slurry (Solids concentration $=25 \mathrm{wt}$. $\% ; \mathrm{pH}=8.6 ;$ Temperature $=70^{\circ} \mathrm{C}$ )

\begin{tabular}{|c|c|c|c|c|c|c|}
\hline & & \multicolumn{5}{|c|}{ Readings (Engineering Unit) at different time (minutes) } \\
\hline Spindle \# & Speed (RPM) & 5 & 10 & 15 & 20 & 25 \\
\hline 3 & 10 & 26.2 & 27.1 & 29.2 & 29.9 & 32.2 \\
\hline 3 & 12 & 23.0 & 22.4 & 22.5 & 25.1 & 26.8 \\
\hline 3 & 20 & 48.0 & 51.9 & 46.0 & 42.9 & 41.5 \\
\hline
\end{tabular}

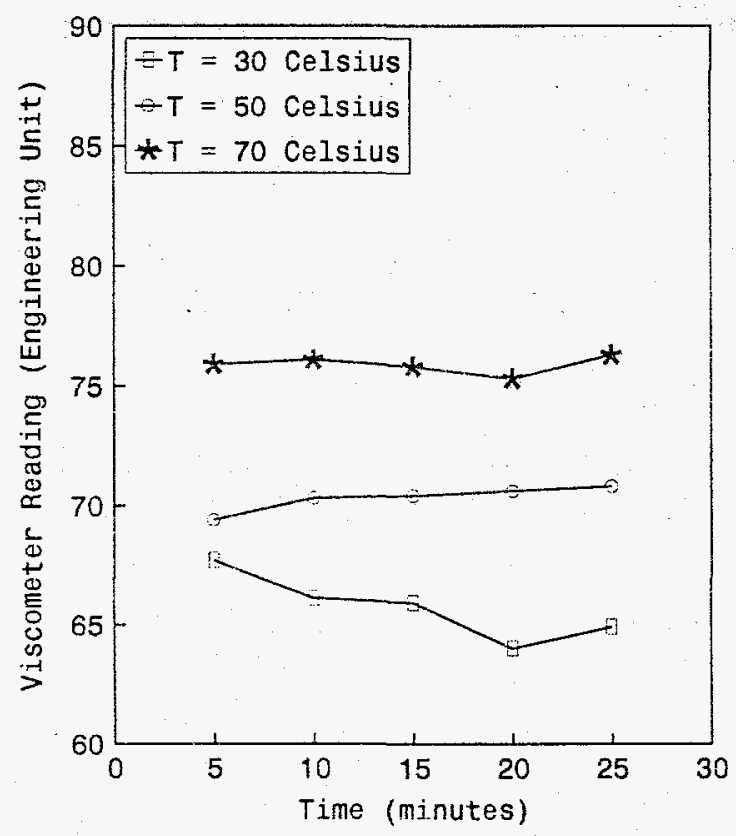

Figure 17. Temperature effect on the viscosity of Hanford slurry (engineering reading) (solids concentration $=17 \quad$ wt. $\%$; $\quad p h=10 ; \quad$ spindle $=3$; speed $=30 \mathrm{rpm}$ ). 


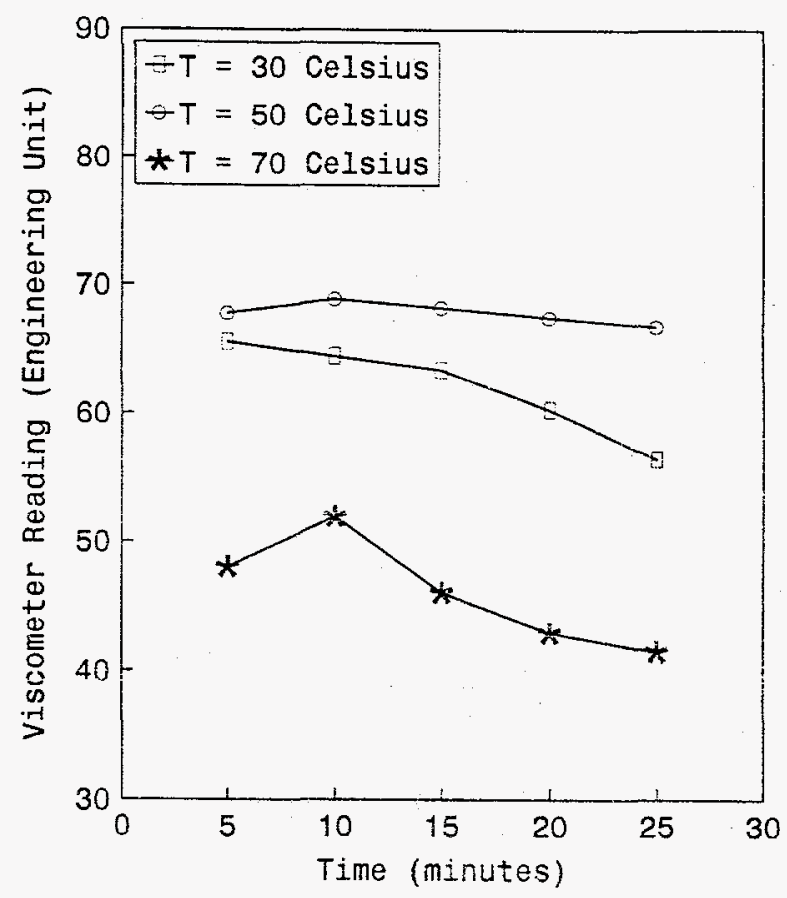

Figure 18. Temperature effect on the viscosity of SRS slurry (engineering reading) (solids concentration $=25$ wt. $\% ; \quad p h=8.6$; spindle $=3$; speed $=20 \mathrm{rpm}$ ). 


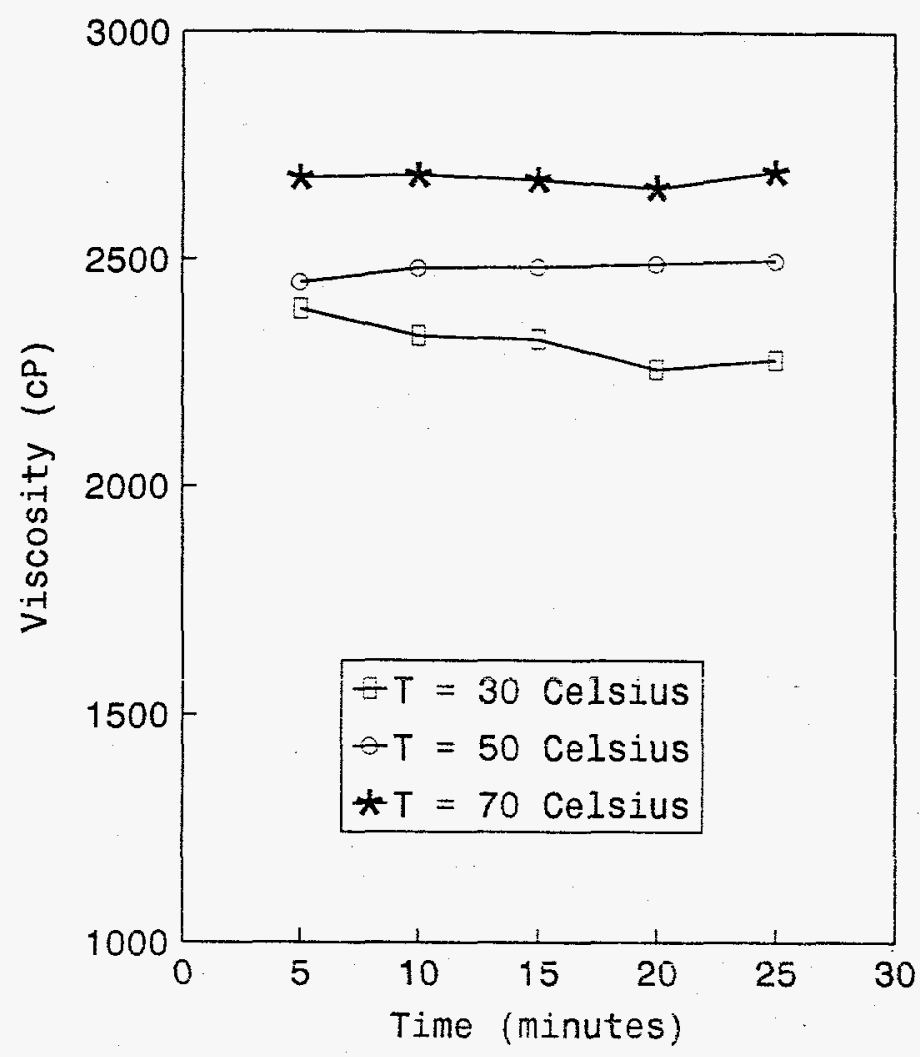

Figure 19. Temperature effect on the viscosity of Hanford slurry (solids concentration $=17$ wt. \%; $\mathrm{pH}=10$ ). 


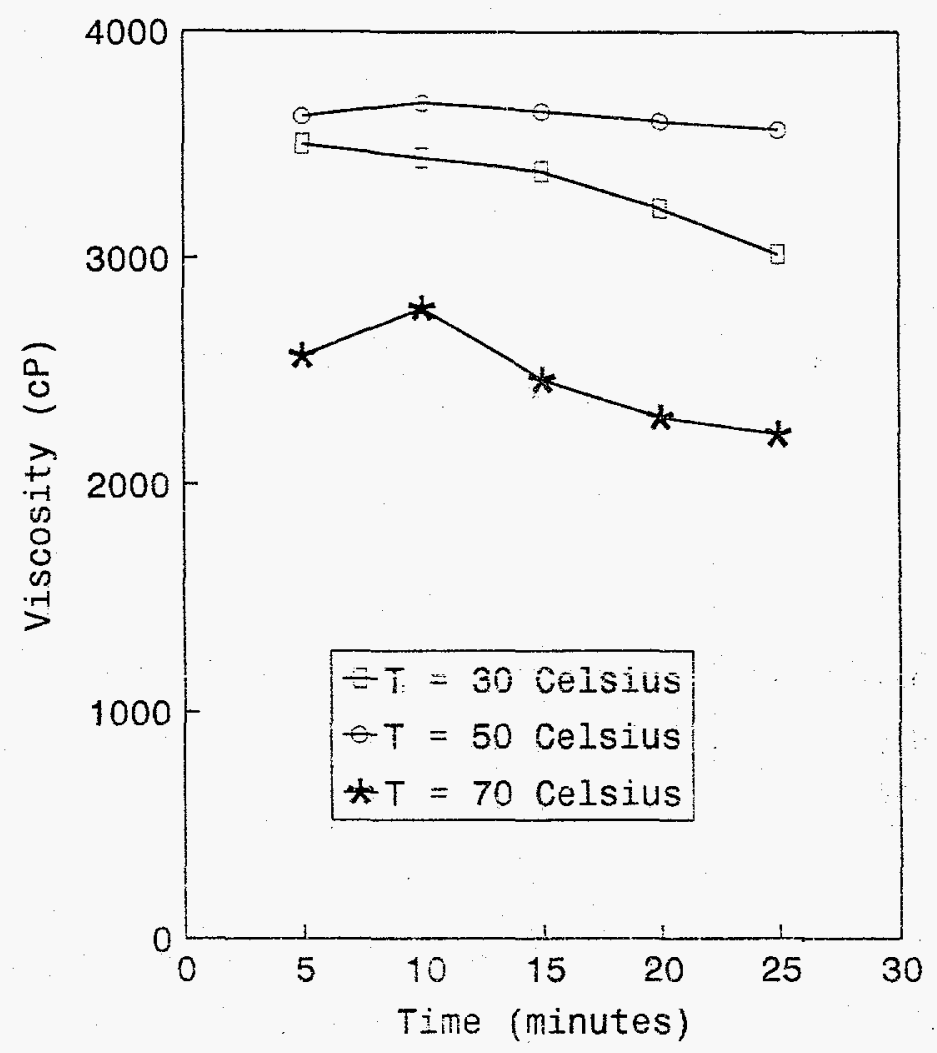

Figure 20. Temperature effect on the viscosity of SRS slurry (solids concentration $=25$ wt. $\% ; \mathrm{pH}=8.6$ ).

\subsection{RESULTS AND DISCUSSIONS}

For both the SRS and Hanford slurries, the experimental observations indicate that the viscosity of the slurry is strongly dependent on the solids concentration, especially in the high solids concentration range. For example, for the SRS slurry, at $10 \mathrm{wt} . \%$ solids concentration, the viscosity of the slurry is approximately $10 \mathrm{cP}$, while the viscosity is as high as $50 \mathrm{cP}$ at $14 \mathrm{wt} \%$ solids concentration (see Figure 8). A much higher viscosity, $1450 \mathrm{cP}$, was observed when the solids concentration increased to $17 \mathrm{wt} \%$, as can be seen in Figure 15. Experimental observation indicates that the relationship between the viscosity of the slurry and the concentration of the slurry is an exponential function. This is shown in Figures 8 and 10. For the SRS slurry, the exponential index is a constant because Figure 9 shows a linear relationship between the viscosity and the concentration. On the other hand, the exponential index for the Hanford slurry seems to be a function of other related factors. This is indicated by the non-linear relationship shown in Figure 11. The details of the mathematical equations with respect to these relationships are presented in Section 6.

The second factor that affects the slurry viscosity is its $\mathrm{pH}$ value. Figure 12 shows the effect of $\mathrm{pH}$ on the SRS slurry. The data were obtained at different $\mathrm{pH}$ adjusted by both sulfuric acid and 
sodium hydroxide. In both $\mathrm{pH}$ cases, the data indicate that the viscosity of the slurry increases with the $\mathrm{pH}$ value. Lower viscosity was observed during the addition of sodium hydroxide. Moreover, there are some dilution effects on the concentration of the slurry during the addition of sulfuric acid. The effect is not important, however, because the amount of the added sulfuric acid is much smaller compared to sample volume.

The results obtained from the addition of sodium hydroxide indicate that the effect of the $\mathrm{pH}$ on the viscosity of the slurries is due to chemical actions rather than physical dilution because the $\mathrm{NaOH}$ addition did not cause any concentration drop in the slurry. It should be noted that the $\mathrm{pH}$ effect on viscosity has different mechanisms for different slurry types. We have observed that there is a direct proportional relationship between viscosity and $\mathrm{pH}$ for the SRS slurry (see Figure 12), but there are viscosity peaks in the Hanford slurry in the pH range of 7 to 8 (see Figure. 13).

Compared to the effects of solids concentration and the $\mathrm{pH}$ value, the temperature of the slurry seems to have had less effect on the viscosity of the slurry. However, the changes in viscosity due to temperature increases are still considerable in terms of the actual operating conditions. For SRS slurry simulant, the following phenomena are observed: In Figure 14, it is evident that the viscosity increases by approximately $30 \%$ when the temperature is raised from 25 to $66^{\circ} \mathrm{C}$. It has been observed that at high solids concentration (Figures 15, 18, and 20), the effect of temperature on the viscosity is opposite to that which occurs at the low concentrations. These phenomena need to be verified in future work by testing other slurry samples at different concentrations. For the Hanford slurry, the viscosity increases as the temperature increases in both the low- and highconcentration slurries (Figure 16, 17, and 19). 


\subsection{EXPERIMENTAL STUDY USING THE PIPELINE FLOW SYSTEM}

To run the experiments at continuous flow conditions, a pipeline testing loop was used. This setup consisted of a continuous flow system for measuring pressure drop along the test tube. Rheological properties were obtained from the pressure drop data. The test loop consisted of a 2.14-m-long horizontal stainless steel pipe with an inside diameter of $0.025 \mathrm{~m}$. A 4-m-long tube (with the same diameter as the test loop) was installed between the slurry pump and the test tube to enhance the mixing of the slurry and eliminate the entrance effect. The stainless steel pipe was electrically heated to maintain the inside mixture at the specified temperature. The outside of the test loop was insulated with thermal insulation materials.

The procedure used to run the pipeline system was as follows:

1. Mix the slurry at the specified concentration and load the slurry into the slurry pump reservoir;

2. Open the valve at the reservoir exit;

3. Turn on the slurry pump at the specified Hz number on the pump's remote controller;

4. Adjust the pump speed according to the required slurry flow rate:

5. Turn on the heating equipment to heat up the slurry to the specified temperature;

6. Adjust the coolant flow rate to control maintain a constant temperature;

7. Activate the data acquisition system;

8. Activate the pressure transducer and Am indicator;

9. Observe the slurry flow rate, pressure drop, temperature, and the pressure at the purnp exit;

10. Take data until the above observations reach their stable values.

\subsection{PRESSURE DROP MEASUREMENT}

The pressure drop along the test tube was measured using a pressure transducer. The transducer uses two plastic tubes ( $2 \mathrm{~m}$ long and $1 / 4 \mathrm{in}$. in diameter) connected to the ends of the test section as pressure sensors. The plastic tube and the transducer were filled with water (assuming that water is an incompressible fluid). The transducer was routinely calibrated with water.

The transducer converted the pressure drop measured from the test tube into an electrical signal $(\mathrm{Am})$ and displayed the signal on an indicator. The pressure transducer was calibrated by taking readings at various heights in the water column. The relationship between the Am reading and the pressure reading of inch-water is a linear function with constant that has been determined by routine calibration. 


\subsection{PARAMETRIC INVESTIGATIONS}

The SRS slurry was measured in the pipeline system under various experimental conditions. For these experiments, four parameters were investigated to examine their effects on the pressure drop of the slurry. These parameters included slurry flow rate, solids concentration, temperature, and $\mathrm{pH}$ value. The parameter ranges covered by the experiments are shown in Table 18.

Table 18.

Experimental Cases in the Pipeline Flow System

\begin{tabular}{|l|l|l|l|l|l|l|l|}
\hline Experiment No. & 1 & 2 & 3 & 4 & 5 & 6 & 7 \\
\hline Concentration (wt. \%) & 0 & 10 & 25 & & & & \\
\hline $\mathrm{pH}$ & 13.5 & 11.2 & 8 & & & & \\
\hline Temperature $\left({ }^{\circ} \mathrm{C}\right)$ & 25 & 35 & 55 & & & & \\
\hline Flow rate $(\mathrm{L} / \mathrm{min})$ & 5 & 10 & 15 & 20 & 25 & 30 & 35 \\
\hline
\end{tabular}

The effect of the solids concentration on the pressure drop is shown in Figure 21, in which water (solids concentration $=0$ ) is used as a baseline to compare it with the slurry with different solids concentrations. From this figure, we can see that with the increase of solids concentration in the slurry, the fluid flow inside the tube became more and more difficult to move due to the increase in slurry viscosity and shear stress, which resulted in the higher pressure gradient along the pipeline. 


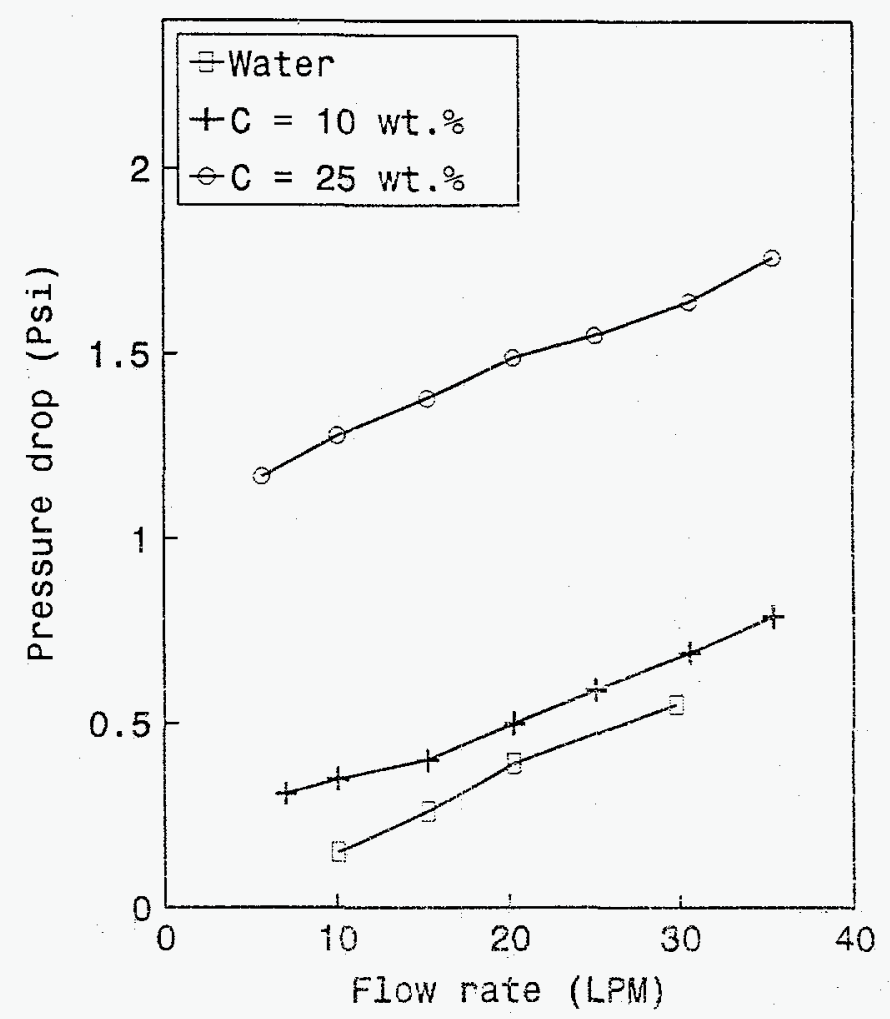

Figure 21. Pressure drop as function of slurry flow rate at different solids concentrations (SRS slumy).

The $\mathrm{pH}$ effect on the slurry viscosity is presented in Figure 22, which shows data measured at three $\mathrm{pH}$ levels and a constant solids concentration of $25 \mathrm{wt} . \%$. These measurements were conducted under the constant temperature of $25^{\circ} \mathrm{C}$.

The results obtained from the pipeline system are consistent with those measured using the rotational viscometer-that is, the viscosity of the SRS slurry increases when its $\mathrm{pH}$ increases. For example, at a medium-high slurry flow rate of $20 \mathrm{~L} / \mathrm{min}$, the pressure drop increases about $50 \%$ at $\mathrm{pH}=13.5$ compared to that at $\mathrm{pH}=8$. We did not test the slurry under a $\mathrm{pH}$ value lower than 8 because of the possibility of corrosion of the pump due to the acidic slurry.

The effect of temperature on the pressure drop of the slurry was examined at three levels $-25^{\circ} \mathrm{C}$, $35^{\circ} \mathrm{C}$, and $55^{\circ} \mathrm{C}$, under a constant slurry concentration of $25 \mathrm{ut} . \%$. These measurements were conducted under a constant $\mathrm{pH}$ of 13.5. The experimental observations are shown in Figure 23. At the particular solids concentration and $\mathrm{pH}$, a higher pressure drop was observed at higher temperatures. In this figure, it can be noted that the pressure drop was 1.7 psi at room temperature and 2.8 psi at $55^{\circ} \mathrm{C}$ under the same slurry flow rate.

All the investigations of solids concentration, $\mathrm{pH}$, and temperature were accomplished by varying the slurry flow rate. In both of the cases run, the relationship between the slurry velocity and pressure drop is indicated by an approximate linear function in a certain parameter range. 
The trend exhibited by the pressure drop according to the slurry flow rate can be observed in Figures 21, 22, and 23.

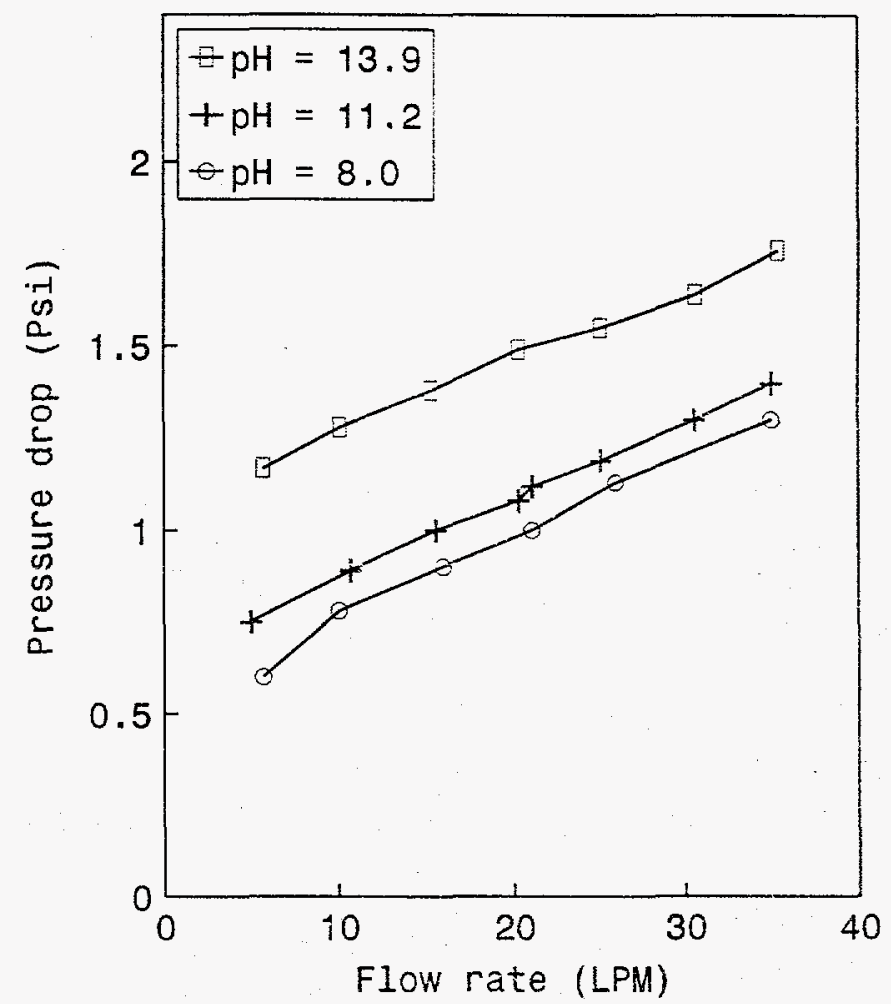

Figure 22. Effect of pH on the viscosity of the SRS slurry simulant. 


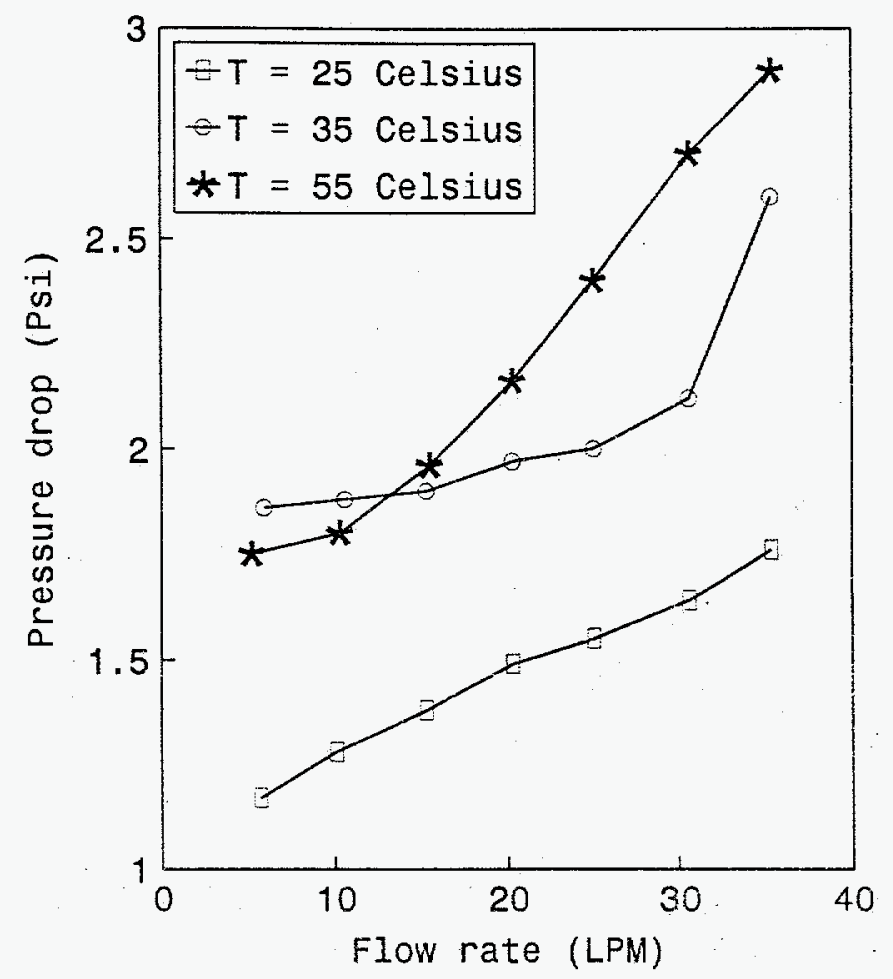

Figure 23. Effect of temperature on the viscosity of the SRS slurry simulant.

A mathematical model has been developed to correlate the measured pressure drop with the shear stress of the slurry applied on the internal pipe wall when the slurry flows through the pipe: The model is described by the following equations:

$$
\begin{gathered}
-\pi D L \tau_{w}+\frac{\pi}{4} D^{2}\left(P_{1}-P_{2}\right)=0 \\
\tau_{w}=\frac{D\left(P_{1}-P_{2}\right)}{4 L}
\end{gathered}
$$

where $\pi=3.14, \mathrm{D}$ is the diameter of the test tube, and $\mathrm{L}$ is the length of the test tube. The difference of $P_{1}$ and $P_{2}$ is the measured pressure drop along the test tube. The $\tau_{w}$ is the shear stress applied on the tube wall by the slurry due to its viscosity. Based on the above equation and the data presented in Figure 21, the relationship between the shear stress and the slurry velocity is shown in Figure 24. 


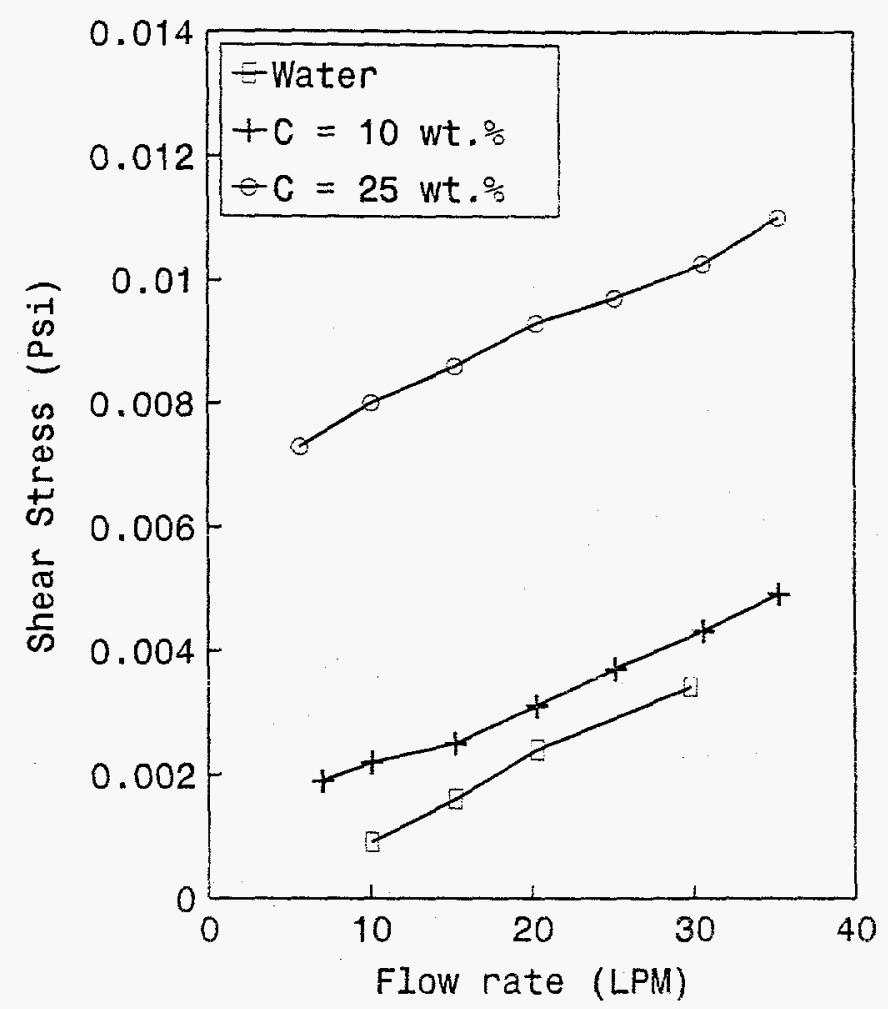

Figure 24. Shear stress as a function of flow rate and solids concentration (SRS slurry at room temperature).

\subsection{RESULTS AND DISCUSSIONS}

For the effect of temperature on the viscosity, there is usually an inverse relationship, that is, the fluid's viscosity decreases as the temperature increases. Typical data are shown in Figure 1, which plots the viscosity of solutions as a function of temperature. We have observed this relationship in our experiments for a $17 \mathrm{wt}$. \% SRS slurry (see Figure 15). On the other hand, we also observed that this relationship is not applicable for the SRS slurry at low solids concentrations $(\sim 12.7 \mathrm{wt} . \%)$ measured using the rotational viscometer and higher solids concentration $(\sim 25 \mathrm{wt}$. \%) measured using the pipeline measurement system.

The effect of $\mathrm{pH}$ on the viscosity of the slurry has been observed in both measurement systems. The assumed mechanism for the $\mathrm{pH}$ effect is that a stern layer and a diffusion electrical double layer are formed around the solid particles at a low $\mathrm{pH}$ value. Thus, the strong aggregation of particles is prevented by the electric force, and the shear stress between the particles is reduced. The strength of this repulsive force is an indication of the $\mathrm{pH}$ value. At high $\mathrm{pH}$ values, on the other hand, the charges are reduced, which increases the possibility of the formation of larger particles and promotes resistance to moving these particles, which results in a high viscosity of the slurry. It is possible that there is a minimum electrical charge for compositions such as the Hanford slurry in a certain $\mathrm{pH}$ range. Therefore, a maximum viscosity would exist for this special condition. Further experiments and analyses are required to clarify this phenomenon. 


\subsection{SLURRY SETTLING TESTS}

An experimental procedure for testing the slurry settling behavior was established. The procedure is as follows:

1. Prepare slurry samples;

2. Measure solids concentration and $\mathrm{pH}$;

3. Mix the samples;

4. Introduce the samples into graduated cylinders;

5. Set timer to zero;

6. Observe the distance change of the interface for the supernate and the sludge;

7. Record the time and the distance.

The tests were conducted using cylindrical containers to determine the terminal velocity of the particles in the slurries. Four 500-mL and three 100-mL cylinders (see Figure 6) were used in the experiments. In the initial tests, samples of the SRS slurry were prepared under 4 pH levels: 5.04 , $7.17,9.16$, and 11.05 with a constant solids concentration of 5 wt. $\%$. The initial experimental observations indicated that the particle settling velocity in the SRS slurry is a function of slurry $\mathrm{pH}$. The results show that high particle settling velocity was observed at a low slurry pH (see Table 19). 
Table 19.

Settling for 5 wt. \% SRS slurry $(500-\mathrm{mL}$ cylinder)

\begin{tabular}{|l|l|l|l|l|l|}
\hline Date & Time & $\mathbf{P h}=\mathbf{5 . 0 4}$ & $\mathbf{P h}=\mathbf{7 . 1 7}$ & $\mathbf{P h}=\mathbf{9 . 1 6}$ & $\mathbf{P h}=\mathbf{1 1 . 0 5}$ \\
\hline $7 / 15 / 97$ & $3: 40 \mathrm{pm}$ & 0 & & & \\
\hline & $3: 45 \mathrm{pm}$ & & 0 & & \\
\hline & $4: 00 \mathrm{pm}$ & $42 \mathrm{ml}$ & $42 \mathrm{ml}$ & & \\
\hline & $4: 15 \mathrm{pm}$ & & & 0 & \\
\hline & $4: 20 \mathrm{pm}$ & & & & 0 \\
\hline & $4: 30 \mathrm{pm}$ & $120 \mathrm{ml}$ & $94.5 \mathrm{ml}$ & $7 \mathrm{ml}$ & $5.5 \mathrm{ml}$ \\
\hline & $5: 00 \mathrm{pm}$ & $194 \mathrm{ml}$ & $141.5 \mathrm{ml}$ & $35 \mathrm{ml}$ & $45 \mathrm{ml}$ \\
\hline & $5: 30 \mathrm{pm}$ & $286.5 \mathrm{ml}$ & $200 \mathrm{ml}$ & $95 \mathrm{ml}$ & $125 \mathrm{ml}$ \\
\hline & $6: 00 \mathrm{pm}$ & $330.5 \mathrm{ml}$ & $242 \mathrm{ml}$ & $133.5 \mathrm{ml}$ & $181.5 \mathrm{ml}$ \\
\hline & $9: 30 \mathrm{am}$ & $452 \mathrm{ml}$ & $400 \mathrm{ml}$ & $322.5 \mathrm{ml}$ & $355 \mathrm{ml}$ \\
\hline & $11: 00 \mathrm{am}$ & $452 \mathrm{ml}$ & $400 \mathrm{ml}$ & $325 \mathrm{ml}$ & $357 \mathrm{ml}$ \\
\hline & $1: 00 \mathrm{pm}$ & $452 \mathrm{ml}$ & $400 \mathrm{ml}$ & $330 \mathrm{ml}$ & $361.5 \mathrm{ml}$ \\
\hline & $2: 00 \mathrm{pm}$ & $453 \mathrm{ml}$ & $401 \mathrm{ml}$ & $331.5 \mathrm{ml}$ & $362 \mathrm{ml}$ \\
\hline & $3: 00 \mathrm{pm}$ & $454 \mathrm{ml}$ & $402 \mathrm{ml}$ & $333 \mathrm{ml}$ & $363.5 \mathrm{ml}$ \\
\hline
\end{tabular}

For the tests in the next step, the samples of the SRS slurry were prepared at higher concentrations-between 6.81 and $13.1 \mathrm{wt} \%$-and the effects of solids concentration and $\mathrm{pH}$ have been examined.

The settling behaviors of the SRS waste slurry in range of concentrations has been tested. Experimental data are presented in Table 20. The settling volume has been correlated as a function of settling time, and the results are presented in Figure 25. Corresponding to each $\mathrm{pH}$ level, the solids concentrations are as follow:

Sample 1, $\mathrm{pH}=5: \quad$ Beaker Weight $=30.10 \mathrm{~g}$

Gross $=66.3 \mathrm{~g}$

Weight (Dry) $=34.05 \mathrm{~g}$

Solids Concentration $=10.9$ wt. $\%$

Sample 1, $\mathrm{pH}=7: \quad$ Beaker Weight $=30.46 \mathrm{~g}$

Gross $=67.7 \mathrm{~g}$

Weight $($ Dry $)=32.95 \mathrm{~g}$ 
Solids Concentration $=6.81 \mathrm{wt} . \%$

Sample 1, $\mathrm{pH}=9: \quad$ Beaker Weight $=30.15 \mathrm{~g}$

Gross $=65.4 \mathrm{~g}$

Weight $($ Dry $)=34.77 \mathrm{~g}$

Solids Concentration $=13.1$ wt. $\%$

Sample 1, $\mathrm{pH}=11: \quad$ Beaker Weight $=30.30 \mathrm{~g}$

Gross $=59.8 \mathrm{~g}$

Weight $($ Dry $)=33.39 \mathrm{~g}$

Solids Concentration $=10.1 \mathrm{wt} . \%$

Table 20.

Measured settling volume $(\mathrm{mL})$ as a function of settling time

\begin{tabular}{|c|c|c|c|c|c|c|c|}
\hline \multicolumn{2}{|c|}{$\mathbf{p H = 5}$} & \multicolumn{2}{c|}{$\mathbf{p H}=\mathbf{7}$} & \multicolumn{2}{c|}{$\mathbf{p H}=\mathbf{9}$} & \multicolumn{2}{c|}{ pH =11 } \\
\hline hrs:min & settling & hrs:min & settling & hrs:min & settling & Hrs:min & settling \\
\hline $00: 00$ & 0 & $00: 00$ & 0 & $00: 00$ & 0 & & \\
\hline $00: 45$ & $19 \mathrm{ml}$ & $00: 30$ & $90 \mathrm{ml}$ & $00: 10$ & $15 \mathrm{ml}$ & $00: 00$ & 0 \\
\hline $01: 15$ & $33 \mathrm{ml}$ & $01: 00$ & $124 \mathrm{ml}$ & $00: 40$ & $82 \mathrm{ml}$ & $00: 30$ & $40 \mathrm{ml}$ \\
\hline $01: 45$ & $47 \mathrm{ml}$ & $01: 30$ & $143 \mathrm{ml}$ & $01: 10$ & $130 \mathrm{ml}$ & $01: 00$ & $110 \mathrm{ml}$ \\
\hline $02: 45$ & $73 \mathrm{ml}$ & $02: 30$ & $192 \mathrm{ml}$ & $02: 10$ & $162 \mathrm{ml}$ & $02: 00$ & $151 \mathrm{ml}$ \\
\hline $19: 45$ & $324: 4 \mathrm{ml}$ & $19: 30$ & $289 \mathrm{ml}$ & $19: 10$ & $242.5 \mathrm{ml}$ & $19: 00$ & $282 \mathrm{ml}$ \\
\hline $20: 45$ & $325 \mathrm{ml}$ & $20: 30$ & $290 \mathrm{ml}$ & $20: 10$ & $247 \mathrm{ml}$ & $20: 00$ & $285 \mathrm{ml}$ \\
\hline $21: 45$ & $327 \mathrm{ml}$ & $21: 30$ & $292 \mathrm{ml}$ & $21: 10$ & $247.5 \mathrm{ml}$ & $21: 00$ & $289 \mathrm{ml}$ \\
\hline $22: 45$ & $329 \mathrm{ml}$ & $22: 30$ & $297 \mathrm{ml}$ & $22: 10$ & $250 \mathrm{ml}$ & $22: 00$ & $291.5 \mathrm{ml}$ \\
\hline $42: 45$ & $352.5 \mathrm{ml}$ & $42: 30$ & $322.5 \mathrm{ml}$ & $42: 10$ & $272.5 \mathrm{ml}$ & $42: 00$ & $317.5 \mathrm{ml}$ \\
\hline $50: 45$ & $357.5 \mathrm{ml}$ & $50: 30$ & $327.5 \mathrm{ml}$ & $50: 10$ & $275 \mathrm{ml}$ & $50: 00$ & $322.5 \mathrm{ml}$ \\
\hline $121: 15$ & $362 \mathrm{ml}$ & $121: 00$ & $333.5 \mathrm{ml}$ & $120: 40$ & $284 \mathrm{ml}$ & $120: 30$ & $335.5 \mathrm{ml}$ \\
\hline $123: 15$ & $364.5 \mathrm{ml}$ & $123: 00$ & $334.5 \mathrm{ml}$ & $122: 40$ & $284.5 \mathrm{ml}$ & $122: 30$ & $335.5 \mathrm{ml}$ \\
\hline $124: 15$ & $364.5 \mathrm{ml}$ & $124: 00$ & $334.5 \mathrm{ml}$ & $123: 40$ & $284.5 \mathrm{ml}$ & $123: 30$ & $335.5 \mathrm{ml}$ \\
\hline $140: 15$ & $364.5 \mathrm{ml}$ & $140: 00$ & $334.5 \mathrm{ml}$ & $140: 40$ & $284.5 \mathrm{ml}$ & $140: 30$ & $336.5 \mathrm{ml}$ \\
\hline
\end{tabular}




\section{Solids Settling Volume as Function of Time}

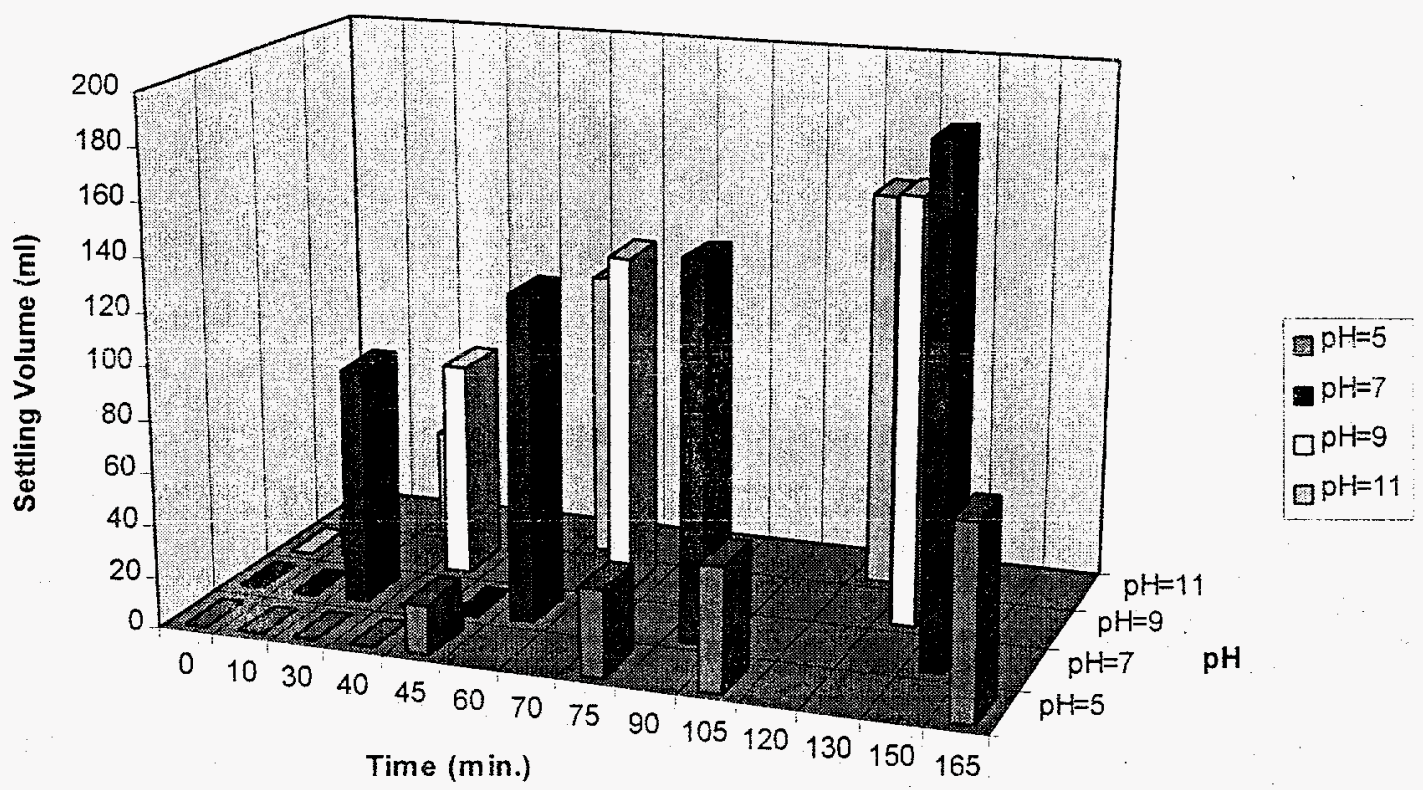

Figure 25. Settling volume as a function of time and $\mathrm{pH}$.

The settling behavior for the Hanford slurries has been measured for four slurry samples. These samples were prepared at different $\mathrm{pH}$ levels of 5.1, 7.3, 9.3, and 11.3. The solids concentrations for the samples were $4.8,5.8,6.5$, and $7 \mathrm{wt}$. \%. Measurements of settling volume as a function of time have been performed in four $500-\mathrm{mL}$ graduated cylinders at a room temperature of $24^{\circ} \mathrm{C}$. Detailed information for the sample concentration analysis is presented in Table 21 , and the measured settling volume and time are given in Table 22.

Table 21.

Hanford sample analysis

\begin{tabular}{|l|l|l|l|l|}
\hline $\mathrm{pH}$ & $\begin{array}{l}\text { Beaker Weight } \\
(\mathrm{g})\end{array}$ & $\begin{array}{l}\text { Total Weight } \\
(\mathrm{g})\end{array}$ & $\begin{array}{l}\text { Weight of Dry Solids } \\
(\mathrm{g})\end{array}$ & $\begin{array}{l}\text { Concentration } \\
\text { wt.\% }\end{array}$ \\
\hline 5.1 & 30.1 & 70.07 & 32.68 & 6.5 \\
\hline 7.3 & 28.7 & 69.08 & 30.65 & 4.8 \\
\hline 9.3 & 30.5 & 66.34 & 32.56 & 5.8 \\
\hline 11.3 & 30.30 & 73.19 & 33.33 & 7.0 \\
\hline
\end{tabular}




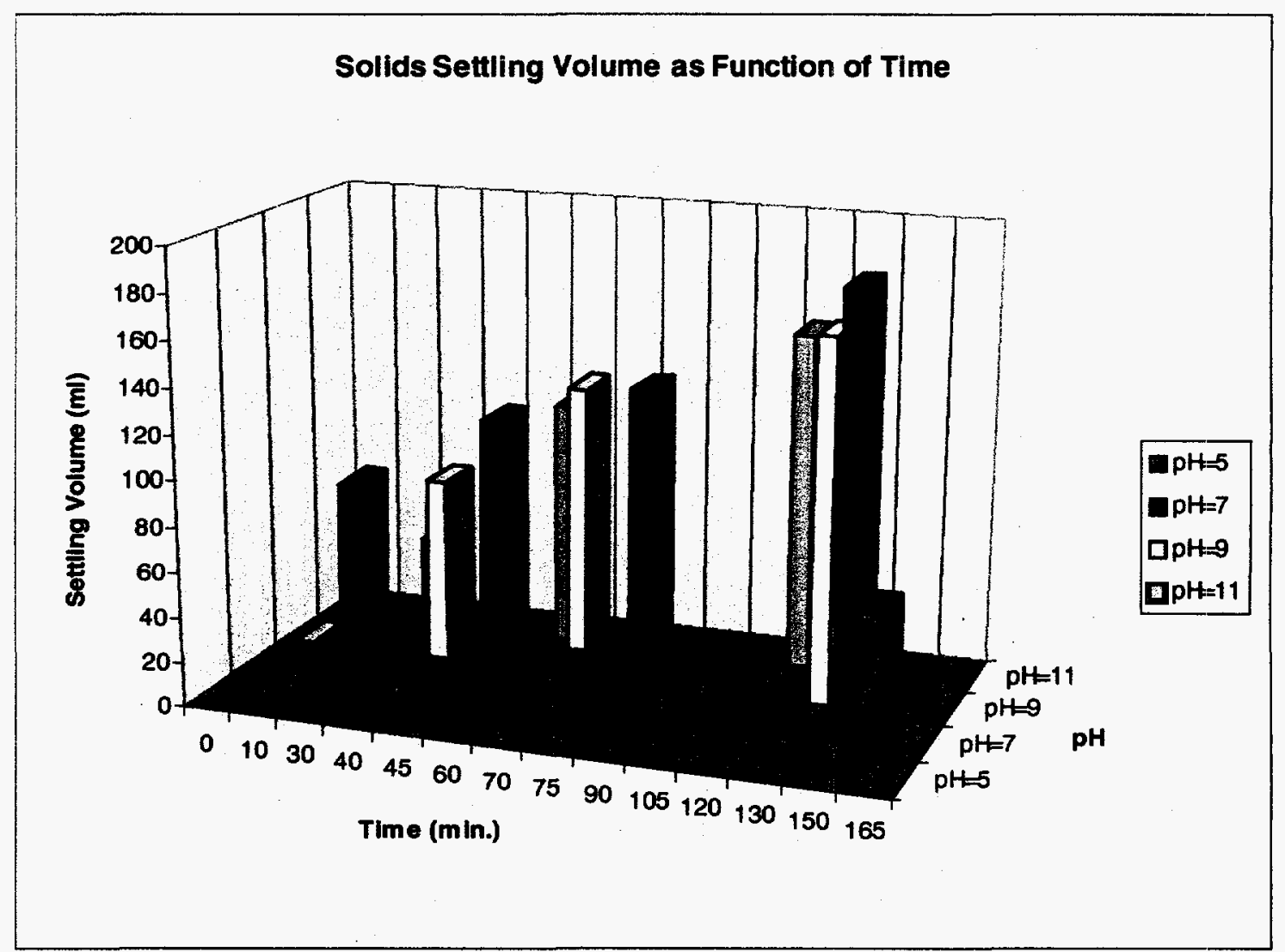

Figure 25. Settling volume as a function of time and pH.

The settling behavior for the Hanford slurries has been measured for four slurry samples. These samples were prepared at different $\mathrm{pH}$ levels of 5.1,7.3,9.3, and 11.3. The solids concentrations for the samples were 4.8, 5.8, 6.5, and $7 \mathrm{wt}$. \%. Measurements of settling volume as a function of time have been performed in four $500-\mathrm{mL}$ graduated cylinders at a room temperature of $24^{\circ} \mathrm{C}$. Detailed information for the sample concentration analysis is presented in Table 21 , and the measured settling volume and time are given in Table 22.

Table 21.

Hanford sample analysis

\begin{tabular}{|l|l|l|l|l|}
\hline $\mathrm{pH}$ & $\begin{array}{l}\text { Beaker Weight } \\
(\mathrm{g})\end{array}$ & $\begin{array}{l}\text { Total Weight } \\
(\mathrm{g})\end{array}$ & $\begin{array}{l}\text { Weight of Dry Solids } \\
(\mathrm{g})\end{array}$ & $\begin{array}{l}\text { Concentration } \\
\text { wt.\% }\end{array}$ \\
\hline 5.1 & 30.1 & 70.07 & 32.68 & 6.5 \\
\hline 7.3 & 28.7 & 69.08 & 30.65 & 4.8 \\
\hline 9.3 & 30.5 & 66.34 & 32.56 & 5.8 \\
\hline 11.3 & 30.30 & 73.19 & 33.33 & 7.0 \\
\hline
\end{tabular}




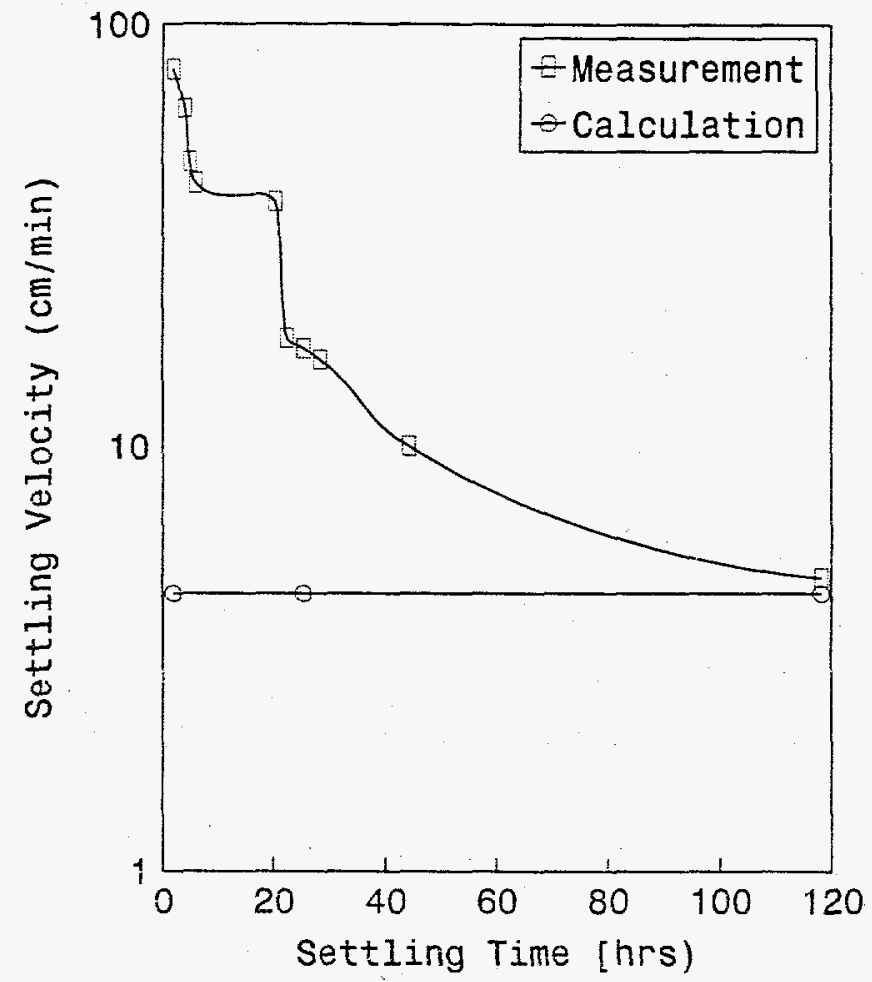

Figure 26. Comparison of measured dynamic settling velocisy and calculated terminal velocity. 


\subsection{DATA ANALYSIS AND CORRELATION}

The experimental data and model predictions for the effect of solid concentration on the viscosity of the SRS slurry are shown in Figures 8 and 9 . The solids concentrations were studied at a constant temperature and $\mathrm{pH}$ value. Experimental observations indicate that the concentration exerts a strong effect on the viscosity of the slurry. When the solids concentration increases to greater than $10 \mathrm{wt} . \%$, the viscosity rises to a dramatically high value. To make a correlation for the experimental data and predict the rheological properties of slurries at high solids concentrations, a mathematical model was selected to describe this rheological behavior:

$$
\mu=A e^{B C} \frac{1}{\left(1-\frac{C}{C_{\max }}\right)}
$$

where $\mu$ represents the apparent viscosity (cP) of the slurry; $\mathrm{C}$ denotes the solids concentration (wt. \%); and $\mathrm{C}_{\max }$ represents the maximum solids concentration the slurry can handle. Parameters $\mathrm{A}$ and $\mathrm{B}$ were determined by performing a Least-Squares fit to the experimental data using this equation. The correlation results under the specification of $C_{\max }=100$ were $A=0.16(\mathrm{cP}$ ) and $\mathrm{B}=0.4$. A comparison of the measured viscosity and the model predictions for typical slurry $\mathrm{pH}$ and operation temperatures is also shown in Figures 8 and 9.

It is interesting to note that in the viscosity model, if the solids concentration was zero (i.e., the slurry turned into a liquid state with a certain $\mathrm{pH}$ value), the viscosity was equal to the value of parameter $\mathrm{A}$, which is only a function of $\mathrm{pH}$ and temperature. If the solids concentration increased to the its maximum value of $\mathrm{C}_{\max }$ (i.e., there is a solids concentration of $100 \%$ in the slurry), the viscosity obtained from the model went up to infinity, which indicates the viscosity of solid state materials.

The Hanford slurry shows different rheological behavior from the SRS slurry; which has been observed, from the experimental investigation (see Figure 10 and 11). There are two features for the Hanford slurry viscosity in its dependency on the solids concentration: (1) the slurry is of much higher viscosity than the SRS slurry at same solids concentration and (2) the solids concentration dependency indicates a more complex exponential function with the viscosity. We have checked the mathematical model Equation (6) with the experimental data measured from the Hanford slurry and found that this model needs to be modified to predict the data.

Based on the special rheological behavior of the Hanford slurry, a mathematical model similar to the SRS slurry equation but with an additional parameter has been developed to correlate the data. The model is described by the following equation:

$$
\mu=A e^{\left(B C+D C^{2}\right)} \frac{1}{\left(1-\frac{C}{C_{\max }}\right)}
$$


where $\mathrm{D}$ is another parameter to be regressed from the data and $\mathrm{C}_{\max }$ is still defined as a maximum solids concentration of $100 \mathrm{wt} . \%$. The parameters correlated to the data have the following values:

$$
\begin{gathered}
A=0.011\left(\mathrm{cP}^{2}\right) \\
B=1.36 \\
D=-0.042
\end{gathered}
$$

Even though we consider this model to be an empirical correlation and no physical explanation exists for these parameters, the format of the model is consistent with that proposed by Marek (1994). The model can also be interpreted at the two extreme points-that is, the zero and $100 \%$ concentrations. The viscosity calculated from this model has been plotted in both Figures 10 and 11. The agreement between the experimental data and the model prediction is reasonable. 


\subsection{MAJOR ACCOMPLISHMENTS AND CONCLUSIONS}

In this experimental investigation, viscosity measurements were performed for two types of simulated defense waste slurries: a SRS slurry simulant and a Hanford slurry simulant. The measurements were conducted in two experimental options. A rotational viscometer was used to measure viscosity under well-defined temperature, solids concentration, and $\mathrm{pH}$ value operating conditions. The solids concentration used for this option was between 5 and $17 \mathrm{wt} \%$. Both the slurries have been investigated under different feed conditions such as temperature and $\mathrm{pH}$ using small amount of slurry. The SRS and Hanford slurries have also been investigated in a pipeline flow system that measured the pressure drop as the slurry flowed through the pipe. The slurry's viscosity can be extracted from the pressure drop data.

These investigations have been performed in relatively wide parameter ranges. The solids concentration of the slurry tested in the pipeline system was as high as $25 \mathrm{wt} . \%$. The slurry pry in both experimental options covered a range of 4 to 13.5. The highest operating temperature was $66^{\circ} \mathrm{C}$ for the rotational viscometer and $55 \mathrm{C}^{\circ}$ for the pipeline svistem.

Slurry settling behavior was tested for both simulants using graduated cylinders. Settling velocity has been observed and correlated as a function of slurry viscosity, concentration, and pH.

Based on the identification of the slurry's rheological behavior, two mathematical models were developed to correlate the data obtained from the rotational viscometer measurements. The model correlated the experimental data very well in the specified parameter range. The experimental data and the modeling results both indicate that the amount of solids present in the slurry exerts the strongest effect on the viscosity, especially in the higher concentration range. For the Hanford slurry, the viscosity can exceed $1500 \mathrm{cP}$ when the solids concentration surpasses 17 wt. $\%$ at room temperature.

The effects of $\mathrm{pH}$ on viscosity were observed in both experimental options, and the results are consistent. We have found that there is a maximum viscosity around the pH range of 7 to 9 for the Hanford slurry. This information is important because it can be used in actual operations to reduce the viscosity of the slurry by adjusting the $\mathrm{pH}$ of the slurry to less than 7 or greater than 9 . Based on the data and the chemical characteristics of the slurry, an assumed mechanism was proposed to explain the $\mathrm{pH}$ effect phenomena. The initial results obtained from this study will be used as a reference for future work involving higher solids concentration and other types of slurries.

The operating temperature used in both experimental options was varied from room temperature to 55 and $66^{\circ} \mathrm{C}$. Within this temperature range, the viscosity of the slurry exhibited an increasing trend at lower solids concentrations and a decreasing trend at higher solids concentration, as observed using the rotational viscometer. In the pipeline measurement system, it has been found that the pressure drop exhibited by the SRS slurry along the test tube increases as the operating temperature rises from 25 to $55^{\circ} \mathrm{C}$ for a $25 \mathrm{wt}$. \% concentration slurry.

Application of these experimental and modeling results to the vitrification melter feed preparation process could modify and enhance the technical base for designing slurry 
transportation equipment and pipeline systems. They can also serve as an important reference for improving waste slurry mixing performance and reducing melter operating limitations. 
Bouzaiene, R. and Hassani, F.P., 1992, "A Selection of Pressure Loss Predictions Based on Slurry/Backfill Characterization and Flow Conditions," CIM Bulletin 4, 63-68.

Ebadian, M.A., 1996, Final Report on the Nitrate to Ammonia and Ceramic/Glass Process. Hemispheric Center for Environmental Technology Center (HCET), Miami.

Marek, J.C., 1995, Rheological Properties of Simulated SRS Vitrification Feeds, Presented at the I\&EC Special Symposium, American Chemical Society, Atlanta, GA..

Marek, J.C., 1994, Baseline Task Technical Plan to Develop Technical Bases for Rheolog: Control of DWFP Melter Feed Preparation Process, WSRC-RP-94-558, Rev. 0. Westinghouse Research Center, Aiken, SC.

Kasturi, G. and Stepanek, J.B., 1972a, "Two-Phase Flow-I. Pressure Drop and Void Fraction Measurement in Concurrent Gas-Liquid Flow in a Coil," Chemical Engineering Science $27,1871-1880$.

Kasturi, G. and Stepanek, J.B., 1972b, "Two-Phase Flow-II. Pressure Drop and Void Fraction Measurement in Concurrent Gas-Liquid Flow in a Coil," Chemical Engineering Science $27,1881-1891$.

Lahey R.T., Jr., Acikgoz, M., and Franca, F.,, 1992, "Global Volumetric Phase Fraction in Horizontal Three-Phase Flow," AICHE Journal 38, 1049-1058.

Lockhart R.W. and Martinelli, R.C., 1949, "Proposed Correlation of Data for Isothermal TwoPhase, Two-Component Flow in Pipes," Chemical Engineering Progress 45, 39-47.

Mao, Fuhe, F. K. Desir and M. A. Ebadian, "Pressure Drop Measurement and Correlation for Three-Phase Flows of viscous fluids in a Horizontal Pipe," Int. J. Multiphase Flow, Voi. 32, No. 2, pp. 397-402 (1997).

Round G.F. and Hessari, A.R., 1987, "Rheology of Coal Slurry: pH and Size Distribution Effects," in Particulate and Multiphase Processes, eds. T. Ariman, and T.N. Veziroglu. Hemisphere Publishing Corporation, New York, 329-340.

Sellgren A., 1987, "Some Temperature Effects on Slurry Rheology in Cold Regions," in Particulate and Multiphase Processes, eds. T. Ariman and T.N. Veziroglu, Hemisphere Publishing Corporation, New York, 235-243.

Shor J. T., W. Suyatno, R. L. Cummins, and L.L Farr, Slurry Transport. Prepared by Oak Ridge National Laboratory, Oak Ridge, Tennessee, 37831. DOE contract \#: DE-AC05$84 \mathrm{OR} 21400$. 